\title{
The Rutgers University Insect Collection (1888-2019): History of a New Jersey Treasure Twice Saved By Dr. David Moskowitz
}

\section{DOI: http://dx.doi.org/10.14713/njs.v5i1.172}

The little-known Rutgers University Insect Collection (1888-2019) is one of the largest and most comprehensive collections of New Jersey insects in the world. It was conceived in 1888 by the Reverend George Hulst, the first director, and the first acting professor of entomology of the Rutgers Department of Entomology. Then beginning in 1889, through the tireless efforts and vision of Professor John B. Smith, the second entomologist at Rutgers, a foundation was built that would take the collection well into the twenty-first century. Over the next 130 years, the collection grew through the efforts of many more pillars of the Rutgers Department of Entomology and now has more than 200,000 insect specimens and continues to grow in breadth, purpose and importance. It is essentially a "library of biodiversity" of the state providing a view into New Jersey's past and present natural history. It also has a storied past and was rescued twice, once from fire in 1903 and then from neglect in 2003. The collection is a legacy to many great Rutgers entomologists and alumni, past and present, that helped build the collection; many who were, and are, renowned pillars in the field of entomology. Their work has had a lasting impact on insect classification, insect disease control, and agricultural production, not just in New Jersey, but across the world. The collection is irreplaceable and is a Rutgers University and a New Jersey treasure.

\section{Introduction}

The little-known Rutgers University Insect Collection (aka the Insect Museum) is one of the largest and most comprehensive collections of New Jersey insects in the world and is more than 130 years old. The collection of more than 200,000 specimens, is essentially a "library of biodiversity" of the state. Many of the insects were collected in places that no longer exist due to 
New Jersey's transition from largely agricultural to highly developed, and the collection reflects that now lost natural history. The collection also continues to grow with new additions added through time. Like other insect collections, it therefore provides a view of what was, allowing a comparison to our current insect fauna, and an understanding of what insects we may have lost and gained. ${ }^{1}$ The collection contains the insects collected by many great Rutgers entomologists and alumni, many who were and are renowned pillars in the field of entomology. Their work has had a lasting impact on insect classification, insect disease control, and agricultural production, not just in New Jersey, but across the world. The collection is irreplaceable and is a Rutgers University and a New Jersey treasure. The collection also has a colorful history and was saved twice, first from fire, and then from neglect. Since its inception in 1888, the Rutgers Insect Collection has been a working collection, used by researchers for many aspects of entomology. It was the goal of the two pioneers that started the collection more than a century ago, Reverend George Hulst and John Smith, that it be a public resource and the collection continues to fulfill that vision to this day.

\section{The Hulst and Smith Early Years of the Collection (1888-1912)}

\footnotetext{
1 I. Bartomeus, et al, "Historical changes in northeastern US bee pollinators related to shared ecological traits," Proceedings of the National Academy of Sciences of the United States of America, 110, no. 12 (2013): 465660; I. Bartomeus, et al, "Historical collections as a tool for assessing the global pollination crisis," Philosophical Transactions of the Royal Society 374 (2018), https://royalsocietypublishing.org/doi/full/10.1098/rstb.2017.0389; Robert Somes, Assistant Zoologist, New Jersey Department of Environmental Protection, Endangered and Nongame Species Program, email message to author, February 26, 2019.
} 

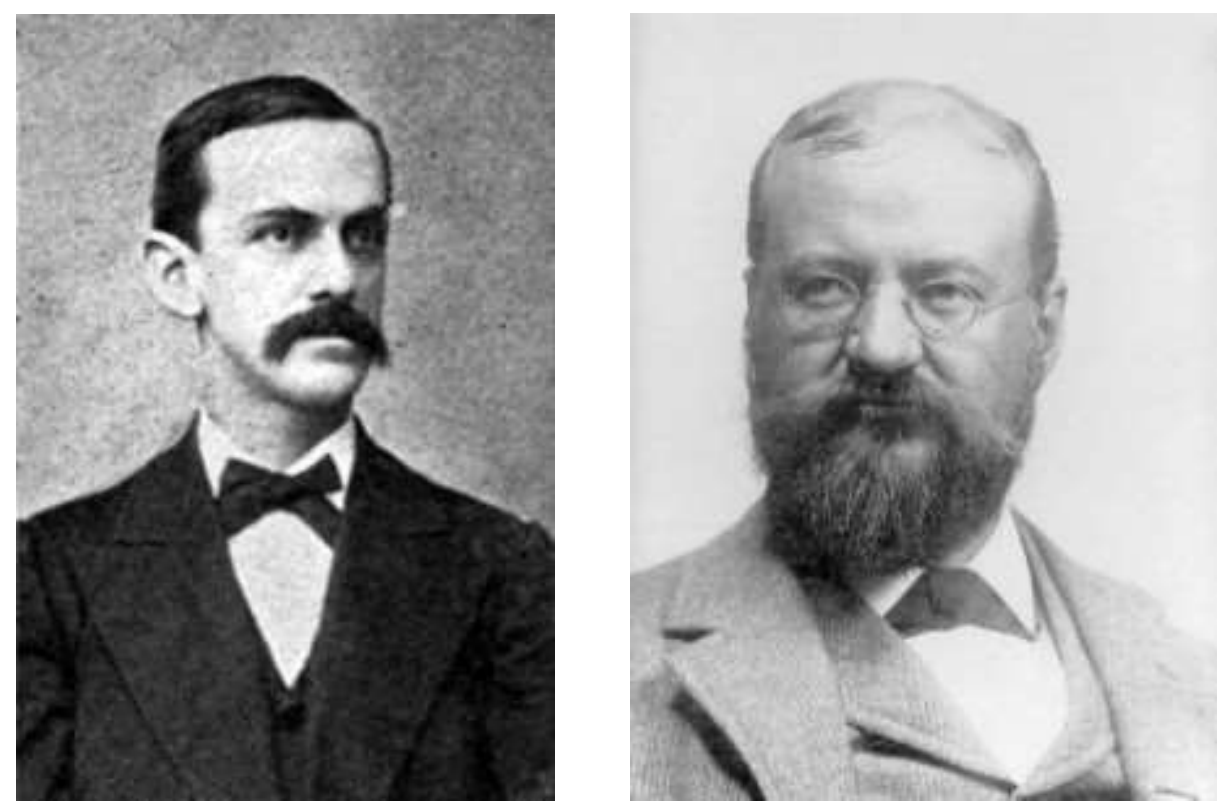

George D. Hulst (left) and John B. Smith (right). Photographs courtesy of the Rutgers University Department of Entomology.

The Rutgers Insect Collection essentially began in 1888 with the creation of the Rutgers Department of Entomology and the appointment of the Reverend George Hulst as the first director and acting professor of entomology. Hulst was a well-known entomologist and specialist in moths (Lepidoptera) and also the pastor of the South Bushwick Reformed Church in Brooklyn, New York. $^{2}$ In 1888, in his first report as entomologist to the New Jersey Agricultural College Experiment Station, and what is likely the first mention of an insect collection at Rutgers, he set the collection in motion, noting:

It is the desire of the Entomologist to form, in conjunction with the Station at New Brunswick, a museum giving, first, a systematic collection of all insects found in the State of New Jersey, and second, a collection of noxious insects in all stages of development, with specimens showing their methods of doing injury, and also specimens of insects parasitic upon them. With this in view, he solicits for his

\footnotetext{
2 A.C. Weeks, "In Memoriam: Rev. Dr. George D. Hulst," Journal of the New York Entomological Society 4 (1900): 248-250.
} 
purpose donations of duplicate or other material from all collectors. Any or all donations will be gratefully received and acknowledged. ${ }^{3}$

Hulst reiterated his vision of a state insect collection in an address to the Sixteenth Annual Session of the State Board of Agriculture in early 1889:

Then, third, it is the intention of the Department to establish a complete museum of insects, as complete as possible. First, to illustrate what insects are found in the State, and have them so arranged as to give anyone who desires, the ability to learn just what an insect is, why it is put where it is, in classification, and all about its relation to other insects, as well as of its own life. And, most important of all, to have in that institution, so that it is illustrated by the eye constantly, to anyone who will look the whole history of every injurious as well as every beneficial insect. ${ }^{4}$

In 1889, after only one year, with the Experiment Station responsibilities interfering with his pastoral duties, Reverend Hulst resigned and was succeeded by John B. Smith. Like many entomologists of the time, Smith had no formal training in entomology or science, but had previously served as a special agent for the Division of Entomology in the United States Department of Agriculture and as an assistant curator in the Division of Insects at the United States National Museum. It seems likely that the early Smith collection (and probably the Hulst collection as well) was housed for a short period in Old Queens Hall, as this served briefly as his office in $1889 .^{5}$

Shortly after Smith accepted the position, the Agricultural Experiment Station and the Entomology Department moved into the newly constructed “Agricultural Hall," built specifically to house the Agricultural Experiment Station and various science departments including entomology. The building which would ultimately be named New Jersey Hall was constructed at

\footnotetext{
${ }^{3}$ Ninth Annual Report of the New Jersey State Agricultural Experiment Station and the First Annual Report of the New Jersey Agricultural College Experiment Station for the Year 1888 (Trenton, New Jersey: State Printing Office, 1889).

${ }^{4}$ State of New Jersey Sixteenth Annual Report of the State Board of Agriculture 1888-1889 (Camden, New Jersey: State Printing Office, 1890).

${ }^{5}$ E.L. Dickerson, "The Work of Professor John B. Smith in Economic Entomology," Proceedings of the Staten Island Association of Arts and Sciences 4 (1912): 18.
} 
the corner of Hamilton Street and Bleeker Place on the Rutgers College campus in New Brunswick, where it still stands today. With funding appropriated by the New Jersey State Legislature, ground was broken for the building on June $1^{\text {st }}, 1888$ and remarkably, it was completed in mid-1889. The ornate building was designed by architect George K. Parsell in the Richardsonian Romanesque style (and would be placed on the National Register of Historic Places on February 24, 1975). The building is constructed of stone and brick from New Jersey and is described as follows:

The foundations are of stone throughout up to the first story line, faced on the outside with rock-faced Newark brown stone. The superstructure is of brick throughout, faced with Trenton pressed brick laid in red mortar, and all windows have stone sills and lintels. ${ }^{6}$

New Jersey Brownstone and Trenton brick were used extensively for public buildings throughout New Jersey and the region. Like many of the insects in the Rutgers insect collection that were collected in places long since lost to development, New Jersey Brownstone from the quarries near Newark, and brick from the brickworks near Trenton, had a similar fate. The quarries and brickworks were largely closed by the turn of the $20^{\text {th }}$ century as development encroached upon them. Owing to its popularity and use in many prominent New Jersey buildings, New Jersey Brownstone has been proposed as the State Rock of New Jersey. ${ }^{7}$

\footnotetext{
${ }^{6}$ Tenth Annual Report of the New Jersey State Agricultural Experiment Station and the Second Annual Report of the New Jersey College Agricultural Experiment Station for the Year 1889 (Camden, New Jersey: State Printing Office, 1890).

7 "Brownstone: The State Rock of New Jersey," New Jersey Department of Environmental Protection, 28 February 2019, https://www.nj.gov/dep/njgs/enviroed/infocirc/brownstone.pdf.
} 


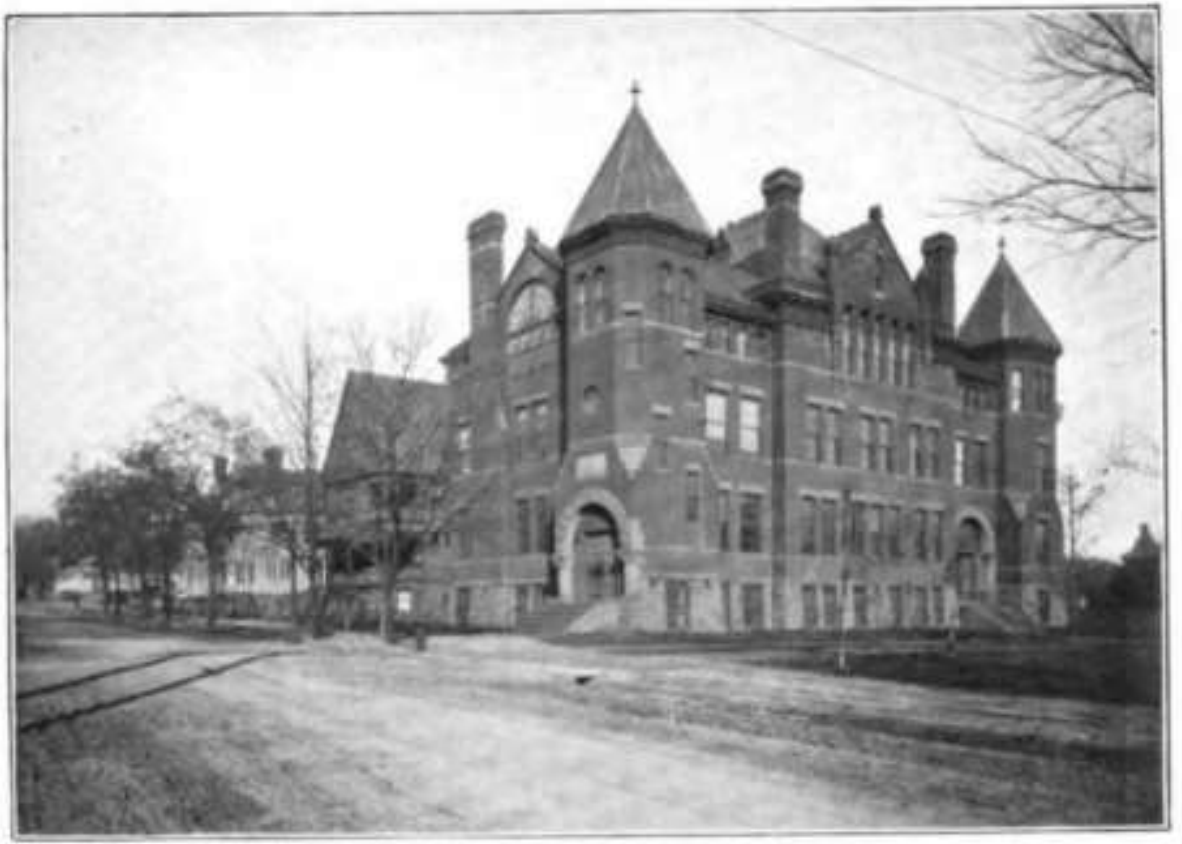

Fa, 1, -New drRsey Stations-Labonatom Bumona.

Photograph, circa 1900, of New Jersey Hall, which housed the New Jersey Agricultural Experiment Station, the Entomology Department, and the Rutgers Insect Collection. Courtesy US Department of Agriculture.

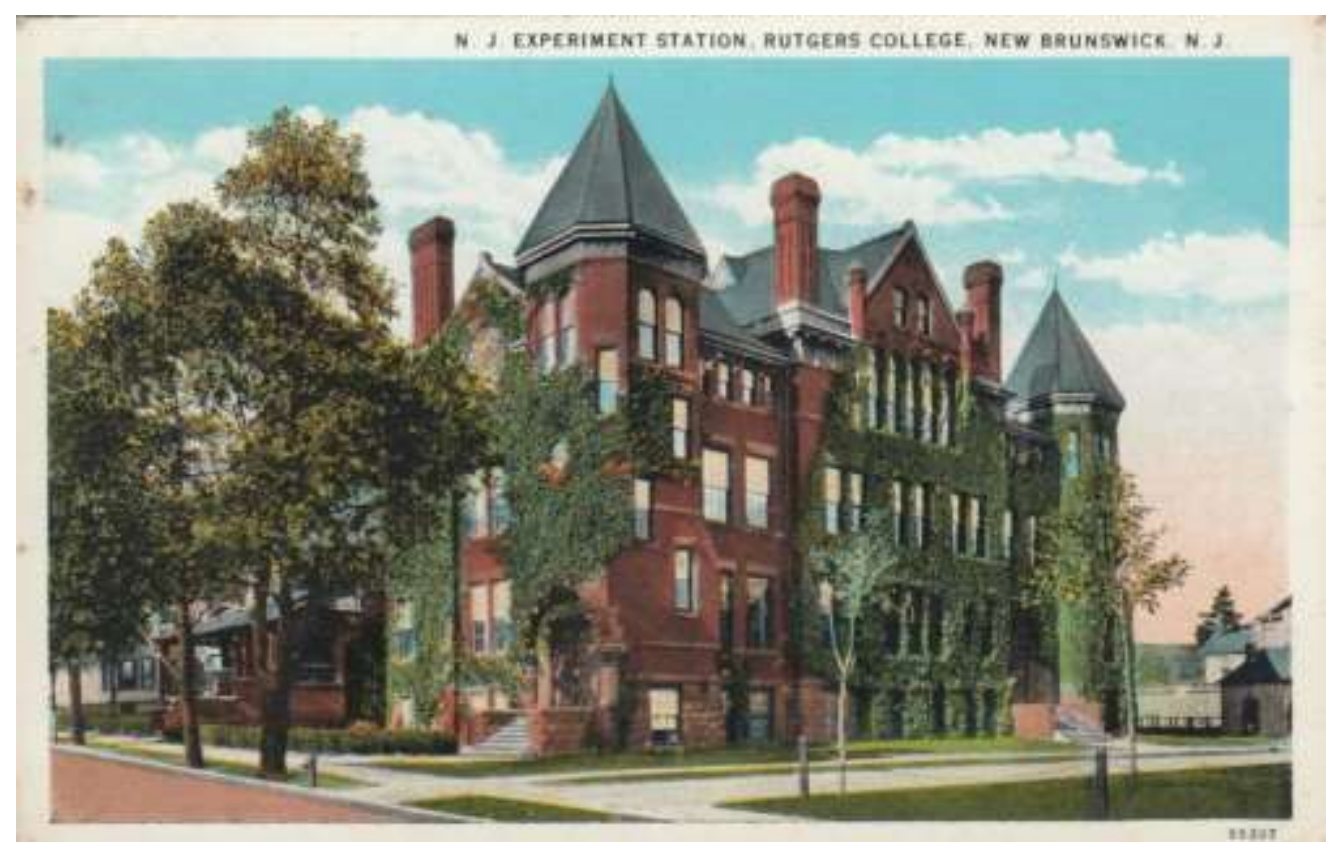

Postcard circa 1925 of New Jersey Hall, which housed the New Jersey Agricultural Experiment Station, the Entomology Department, and the Rutgers Insect Collection. Personal collection of the author. 
Before even being officially appointed as the new entomologist in March 1889, Smith called upon farmers across New Jersey to send him injurious insects with specific directions on how to mail them in a circular titled Entomological Inquiries and Suggestions. ${ }^{8}$ This is likely one of the earliest examples of "citizen science:"

It is a manifest impossibility for the Entomologist to be all over the state hunting injurious insects; he must depend largely upon the farmer to bring them to his notice...Do not waste time in describing insects. Send specimens, and send plenty of them. If an insect is really injurious, it is as easy to get a dozen as it is to get one, and it makes it a great deal easier for the Entomologist. He wants two or three to be put in alcohol, so he will know him next time; the others he wants to try and bring to maturity, or to describe or figure so as to complete his knowledge of them. Such specimens, if dead, should be packed in some soft material, as cotton or wool, and put into a stout tin or wooden box. They go by mail for one cent per ounce. Never send insects loose in a letter! The postal clerk always smashes them flat, so they are never of any use as specimens, and frequently not recognizable. With the specimen send also, so far as possible, a sample of the kind of injury caused by it - a bored twig or root, or gnawed stem, fruit or leaf - anything to show how the insect works. If at all possible send the insects alive, along with a supply of their ordinary food sufficient to last during the journey. Pack them into a tight box, and do not punch air holes into it. Insects need very little air, and the tight box keeps the food moist. Send with the insect and account of what you know of it; how it works - whether on leaves, twigs or fruit; whether above ground or underground; how long you have known it; how much damage it has done; what experiments looking to its destruction have been made, and what the result has been. Such facts are often not only of the highest scientific interest, but also of the greatest practical importance. ${ }^{9}$

As the newly appointed entomologist, in 1890, Smith lamented about the lack of an insect collection and conditions of New Jersey Hall in his first Report of the Entomologist to the New Jersey Agricultural College Experiment Station:

My appointment as Entomologist to the Station took effect April 1st, 1889, and on that day I assumed the duties of the office. The station building was then not yet completed, and the facilities for effective work were therefore not as good as they became later in the season. There were little in the way of apparatus or material for collecting and preserving specimens, and no collection of any kind. My first duty was, therefore, to secure the necessary facilities for work...Materials for collecting

\footnotetext{
8 J.B. Smith, "Entomological Suggestions and Inquiries," New Jersey Agricultural Experiment Station Bulletin 55 (March 28, 1889).

9 “Citizen Science," National Geographic Society, 28 February 2019, https://www.nationalgeographic.org/encyclopedia/citizen-science/.
} 
and preserving insects were also purchased, and before the opening of the season I was in fair condition for work. ${ }^{10}$

Under a section titled COLLECTIONS, Smith continued to articulate his vision of the insect collection building upon his earlier call to farmers to supply him with specimens and information about their life history:

A working collection of insects is a necessity for the Department. It is manifestly impossible that any single person can remember the thousands of species of insects found in our state and the identification from published data is often tedious and unsatisfactory. I have therefore devoted all spare hours to collecting, and have accumulated a large mass of material which will join the nucleus of a good general collection. At present the material is still in a somewhat chaotic state since there has not been time to work it over and have it properly identified.

Supplementary to this collection, which will facilitate the work of the entomologist, there will be a collection of quite a different nature for the benefit of the farmer. In this it will be attempted to show by specimens and figures the principal injurious insects, their methods of work, their early stages and such other information as can be given by means of a collection. The object will be to enable the farmer to recognize the injurious species, not only in the insect form but also from the nature of the injuries caused by them. The formation of such a collection is necessarily a slow process, but the scheme of work embraces constant additions to it.

In 1891, Hulst and Smith were awarded Honorary Doctoral degrees from Rutgers College: Smith, a Doctor of Science (Sc.D.), and Hulst, a Doctor of Philosophy (Ph.D.). ${ }^{11}$ Smith continued developing the insect collection and in his Report of the Entomologist to the New Jersey Agricultural College Experiment Station for 1891 described his ongoing collecting efforts and the growth of the collection:

In the course of my fieldwork I have been at some pains to collect specimens, not only of the injurious insects, but of their work whenever that was possible. I have in this way accumulated a great mass of valuable material, and a considerable proportion of it is well arranged in boxes in such manner as to enable anyone interested to become at once familiar with the insects infesting special crops in all their stages. Thirty-three cases of this character have been prepared and are open

\footnotetext{
${ }^{10}$ J.B. Smith, Report of the Entomologist in Tenth Annual Report of the New Jersey State Agricultural Experiment Station and the Second Annual Report of the New Jersey College Agricultural Experiment Station for the Year 1889 (Camden, New Jersey: State Printing Office, 1890), 241-244.

${ }^{11}$ Catalogue of the Officers and Students of Rutgers College at New Brunswick, 1891-1892 (Rutgers University, 1891).
} 
for examination by all interested. A considerable addition to the list of insects of New Jersey has been made, and a great advance is to be noted in the arrangement of the collection generally.

I have continued my attendance at the meetings of the Entomological Society, at Newark, and less regularly at the New York and Philadelphia Societies, and from the members have secured many specimens for the collection. This, the museum branch of the Department, has received considerable attention; but the work has been largely confined to the accumulation of material, there being no sufficient number of boxes for its display until late in the year. Now, however, cabinets and boxes are at hand, and I hope, during the ensuing winter, to get a large part of the collections into good shape. ${ }^{12}$

About the same time, Hulst donated a large portion of his insect collection to Rutgers, greatly expanding the holdings. Smith described the collection in the 1892 Entomological News:

Dr. Geo. D. Hulst has donated his collection of Lepidoptera to Rutgers College. He will retain for the present the families in which he is working, but everything else goes to the college. The collection is one of the richest in Catocala, and contains a very large number of types in the Geometridae and Pyralidina. There are nearly 2500 named species and much undetermined material, some yet undescribed. ${ }^{13}$

By 1892, Smith noted "Laboratory work has continued in the directions indicated in the previous reports, and a really good collection is gradually accumulating." ${ }^{14}$ The following year, Smith described his pioneering use of photography for the collection:

The use of photography in illustrating insects and their work has occupied a portion of the time of the Entomologist, and many good negatives have been obtained. It is obvious that a good picture will be much more easily understood than any possible description, and many of the illustrations used in the reports of the Botanist as well as of the Entomologist are made from photographs taken in the laboratory. An immense advantage is gained by being able to fix permanently such insect injuries

\footnotetext{
${ }^{12}$ J.B. Smith, Report of the Entomologist in Twelfth Annual Report of the New Jersey State Agricultural Experiment Station and the Fourth Annual Report of the New Jersey College Agricultural Experiment Station for the Year 1891 (Trenton, New Jersey: State Printing Office, 1892), 349.

${ }^{13}$ Entomological News and Proceedings of the Entomological Section of the Academy of Natural Sciences of Philadelphia, Volume III (1892), 38.

${ }^{14}$ J.B. Smith, Report of the Entomologist in Thirteenth Annual Report of the New Jersey State Agricultural Experiment Station and the Fifth Annual Report of the New Jersey College Agricultural Experiment Station for the Year 1892 (Trenton, New Jersey: State Printing Office, 1893), 397.
} 
as cannot be preserved, dry or in alcohol, or which lose their characteristic appearance rapidly. ${ }^{15}$

Smith had a specific vision for the economic insect collection. He was also definitely at the forefront of citizen science and was evidently masterful at developing a large network of volunteer collectors to secure specimens for the Rutgers collection. He described these efforts in 1895:

The collection has been greatly increased during the same period, and especially that branch of it which is distinctly economic. Injurious insects have been added in all orders, while a very large collection of specimens illustrating the injury done has been made. I think I can safely say that the economic collection of the New Jersey Agricultural College Experiment Station is not excelled, except in the national collections at Washington, in the United States. This result is largely due to the pleasant relations established with collectors and entomologists at Brooklyn, N.Y., at Newark, N.J., and at Philadelphia, Pa. ${ }^{16}$

In addition to building the specimen collection, Smith was also continuing with the pioneering use of photography for the collection and in the same note described those efforts and the equipment:

The photographic department has been increased by the addition of a Bausch \& Lomb, professional micro-photographic camera, and some of the work done with this is illustrated in the present report. Several other minor pieces of apparatus have also been added to improve the character of the work done. A large number of negatives, illustrating the work of insects and the insects themselves, have been made, and altogether the camera has become a most important adjunct to the field work of the Station.

The following year, in 1896, Smith echoed the continuing growth of the collection and his efforts

to secure specimens from other collectors:

A great deal of material has been added to the economic collections of this department. No opportunity has been missed for obtaining material illustrating all the stages of the injurious insects of the State, or those likely to become so, and whenever possible examples of the injury done by them. Furthermore, it is intended to arrange the collection in such a way that the insects injurious to special crops will all be gathered together; so all the insects injurious to corn will be grouped, and those injurious to apples, and so on through the list. There are now on exhibition

\footnotetext{
15 J.B. Smith, Report of the Entomologist in Fourteenth Annual Report of the New Jersey State Agricultural Experiment Station and the Sixth Annual Report of the New Jersey College Agricultural Experiment Station for the Year 1892 (Trenton, New Jersey: State Printing Office, 1894), 447.

16 J.B. Smith, Seventeenth Report of the Entomologist in Annual Report of the New Jersey State Agricultural Experiment Station and the Ninth Annual Report of the New Jersey College Agricultural Experiment Station for the Year 1885 (Trenton, New Jersey: State Printing Office, 1896), 402-403.
} 
44 arranged cases; at least 10 others in cabinets, and material on hand is sufficient to fill at least 50 additional boxes when opportunity for arranging them can be found.

The Entomologist has continued to derive assistance from collectors and students in Brooklyn, New York, Newark, and Philadelphia; and by attending as many entomological meetings as feasible it has been possible to obtain a great deal of information and material that could not have been gathered in any other way. The gentlemen in these cities in fact constitute a sort of voluntary corps of assistants, and are always ready to do what is possible to secure specimens for the collection of the Experiment Station. ${ }^{17}$
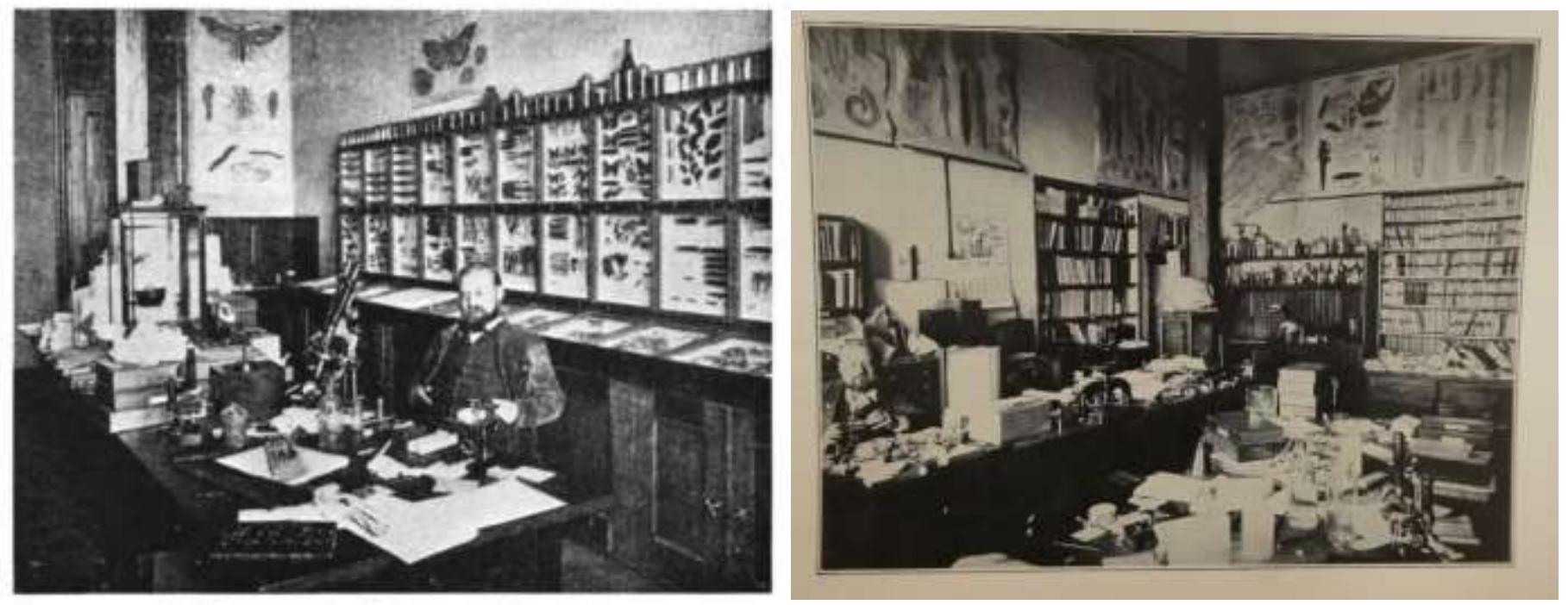

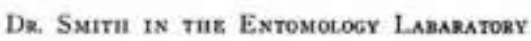

Photographs of Professor John B. Smith in the Entomology Laboratory circa 1900. Note Dr. Smith in the left corner of the photograph on the right, and the wooden insect boxes storing the collection on the table in front. Photographs courtesy of Rutgers University Special Collections and University Archives.

The Rutgers Insect Collection and Smith's vast network of collectors would furnish the material for three seminal Catalogs of New Jersey Insects authored by Smith in 1890, 1899 and

\footnotetext{
${ }^{17}$ J.B. Smith, Eighteenth Report of the Entomologist in Annual Report of the New Jersey State Agricultural Experiment Station and the Tenth Annual Report of the New Jersey College Agricultural Experiment Station for the Year 1885 (Trenton, New Jersey: State Printing Office, 1897).
} 
1910. ${ }^{18}$ By 1900 , the insect collection had grown substantially and was now in two parts: a systematic series for identification and an economic series for pest species $^{19}$ :

In the systematic series are over 4,000 species, represented by at least 25,000 specimens. The economic series is very complete, and represents all the usual injurious insects occurring in the State, in all stages, with specimens of the injury caused by them. Each subject studied is illustrated as far as possible or necessary by microscopic slides, and of these between 2,500 and 2,600 have been accumulated. The division has also nearly 900 lantern slides, illustrating a great range of subjects in economic entomology.

In early 1900, an attempt was made by Harrison Gray Dyar, Jr. to persuade Hulst to donate his collection to the United States National Museum in Washington, D.C. Dyar was a wealthy scientist and served largely in an unpaid position as the Custodian of Lepidoptera at the National Museum for decades. He was brilliant, but also eccentric, arrogant, opinionated and abrasive, and although renowned, was disliked by many entomologists of the time. ${ }^{20}$ On April 23, 1900, not long before his death, Hulst replied to a letter written by Dyar that requested Hulst donate his collection. Hulst responded:

As to giving my types to the National Museum - First, I have no collection - in the proper sense - of my own. All my collection was given years ago to Rutgers College, which may or may not have been wise, but it's done, and all I got now, is simply an addition to that collection. Then, as a member of the Brooklyn Institute, I am in a way bound in honor to do what I can with duplicate material to help along there. And with I may have, if any- and if there are any not in the museum, I will send them to you; though I am certain there will not be many.

The death of Hulst on November 5, 1900 marked another large expansion of the collection with the remainder of his specimens being donated to Rutgers, albeit, with some in poor condition from

\footnotetext{
${ }^{18}$ J.B. Smith, "Catalogue of Insects found in New Jersey," in Report of the Geological Survey (Trenton, New Jersey: State Printing Office, 1890); J.B. Smith, "Insects of New Jersey," in Supplement to the Twenty-seventh Annual Report of the State Board of Agriculture, 1899 (Trenton, New Jersey: State Printing Office, 1900); J.B. Smith, "Report of the Insects of New Jersey," in Annual Report of the New Jersey State Museum (Trenton, New Jersey: State Printing Office, 1910).

19 A.C. True and V. A. Clark, The Agricultural Experiment Stations in the United States (Washington, D.C.: Government Printing Office, 1900), 319.

${ }^{20}$ M.E. Epstein, Moths, Myths \& Mosquitoes. The Eccentric Life of Harrison G. Dyar, Jr (Oxford: Oxford University Press, 2016).
} 
neglect by the executors of his estate. In the 1901 Entomological News in a section called "Notes and News - Entomological Gleanings from All Quarters of the Globe," the accession of the remaining Hulst collection to Rutgers was described:

Prof. Smith informs us that the collection of the late Dr. George D. Hulst is now in his hands at New Brunswick, New Jersey forming part of the Rutgers College Collection.

In December 1891, Dr. Hulst gave his collection to Rutgers, but reserved to himself the right to retain any portion that he wished to study, for such period as he might desire. Pursuant to this gift the Rhopalocera, Sphingidae, Bombycid and Noctuid families were sent to New Brunswick during the early part of 1892. The Tortricids and Tineids followed a little later, but the material was small. The Geometrids and Pyralids were retained under the reservation made in the gift, until the death of Dr. Hulst, who added largely to them during his life time. The executors did not at once deliver the collection to the College, and in the nearly six months during which it had no attention it has become somewhat damaged. Nor is the material in first class condition though much can be greatly improved. It is essentially a study collection from which wings have been taken or scarped to make out details of Venation, and other structural parts removed for mounting on slides.

In the Pyralidae there are 496 species and varieties in 1725 specimens, and of 237 species and varieties there are types.

In the Geometridae there are 721 species and varieties in 2115 specimens, and of these 300 or more are types. The count has been roughly made yet, and the number of species will probably prove greater when all are arranged.

The collection of Rhopalocera contained 443 species and varieties in 1360 specimens: that of Sphingids 60 species and varieties in 120 specimens; that of Catacola 117 species and varieties in 335 specimens, and in this series there are 12 types. The remainder of the collection is merely estimated as yet; but a conservative estimate places the entire collection at over 2237 species and varieties, in over 6600 specimens, with 550 types or over.

New cases are to be provided and the arrangement of the Geometrid collection will begin as soon as possible. ${ }^{21}$

As the collection grew and the work of Smith and the Entomology Department became more widely known, the collection was drawn upon for displays at national and international exhibitions.

21 Entomological News and Proceedings of the Entomological Section of the Academy of Natural Sciences of Philadelphia (1901). 
These exhibits were coordinated with the New Jersey State Museum, where Smith also served as the head of the Department of Entomology. The exhibits were recognized for their excellence with Gold medals at the Buffalo PanAmerican Exposition in 1901 and the Charleston Exposition in 1902, and the Grand Prize and two Gold medals at the Louisiana Purchase Exposition in St. Louis in 1904. The exhibits were apparently so well-received that John B. Smith noted in his 1904 report to the New Jersey State Museum that "The opinion of the scientific world was shown in part by the appreciative notices in their publications and desire of the leading University Museums to purchase the collection." 22 The St. Louis exhibit also contained from the collection "a unique feature... more than 125 plaster casts, representing the work of digging bees, showing the forms of their underground galleries and cells, and their burrowing habitats generally - was the joint work of Dr. Smith and J. Turner Brakeley, of Bordentown."23 Unfortunately, this fascinating aspect of the collection and the entomological displays seem to have been lost to history. ${ }^{24}$ Smith noted the continued growth of the collection and its utility in 1902 in his Report of the Entomologist to the New Jersey Agricultural Experiment Station:

No important single additions were made to the collections, but a great many specimens were added in the course of the year by gatherings made by Mr. Dickerson and myself. Several cases have been rearranged, and scientific study has been made of one group among the owlet moths. A number of boxes were prepared for the State Museum, at Trenton, and thirty-five are now on exhibition. The collections of the Department, belonging partly to the College and partly to the Station, have become of really great importance and value, and deserve a safer housing. The scientific value of the types alone is very great and the study value is difficult to estimate in terms of money. In certain families of the moths, the collection is unsurpassed by any in the United States. ${ }^{25}$

\footnotetext{
22 J.B. Smith, "New Material at St. Louis," in Annual Report of the New Jersey State Museum (Paterson, New Jersey: State Printing Office, 1905), 33.

${ }^{23}$ C.R. Woodward and I. N. Waller, New Jersey's Agricultural Experiment Station 1880-1930 (New Brunswick, New Jersey: New Jersey Agricultural Experiment Station, 1932).

${ }^{24}$ David Parris, New Jersey State Museum Natural History Curator, email message to author, March 19, 2019.

25 J.B. Smith, "Report of the Entomologist," in Twenty-third Annual Report of the New Jersey State Agricultural Experiment Station and the Fifteenth Annual Report of the New Jersey College Agricultural Experiment Station for the Year ending October 31, 1902 (Trenton, New Jersey: State Printing Office, 1903), 442.
} 

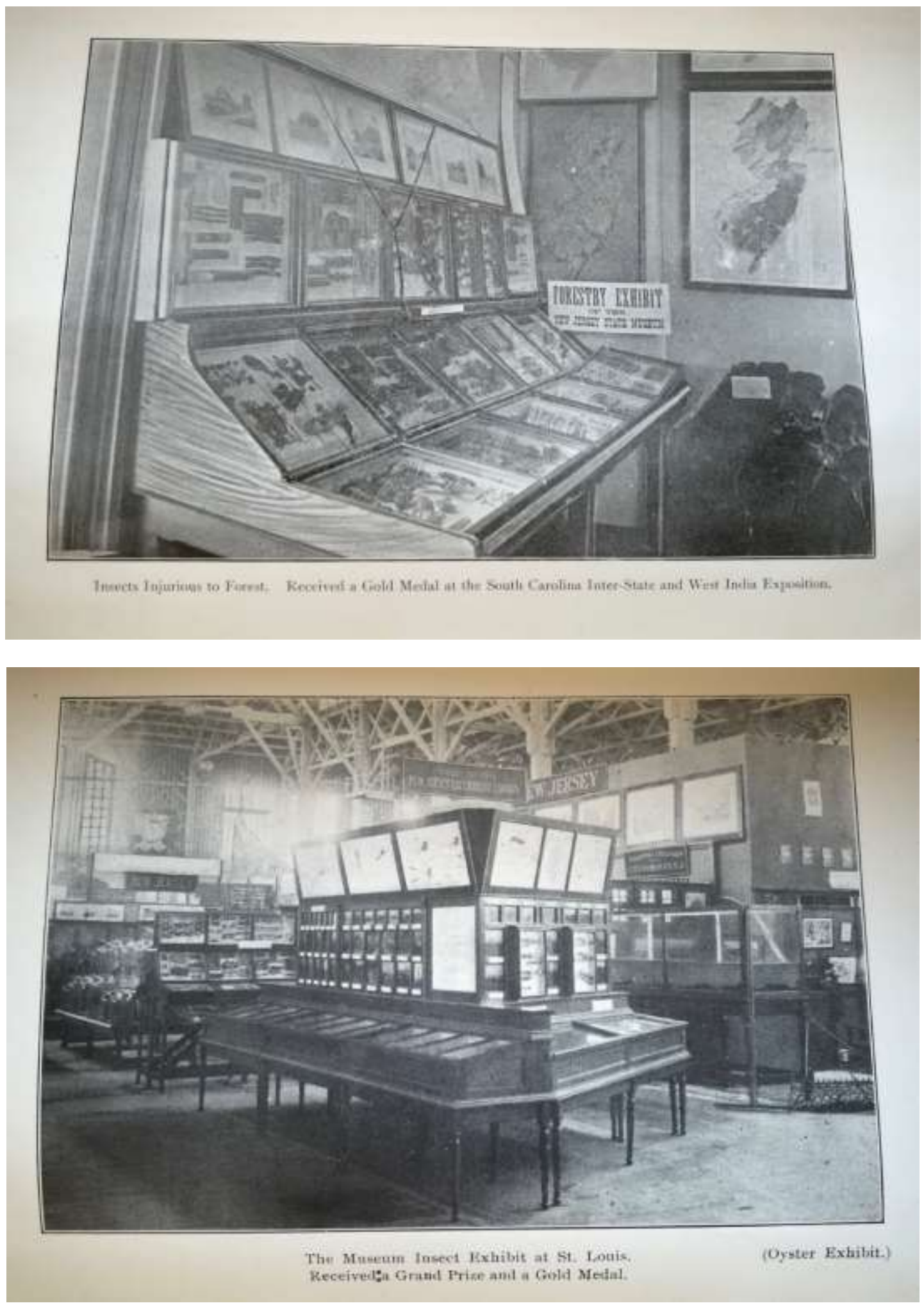


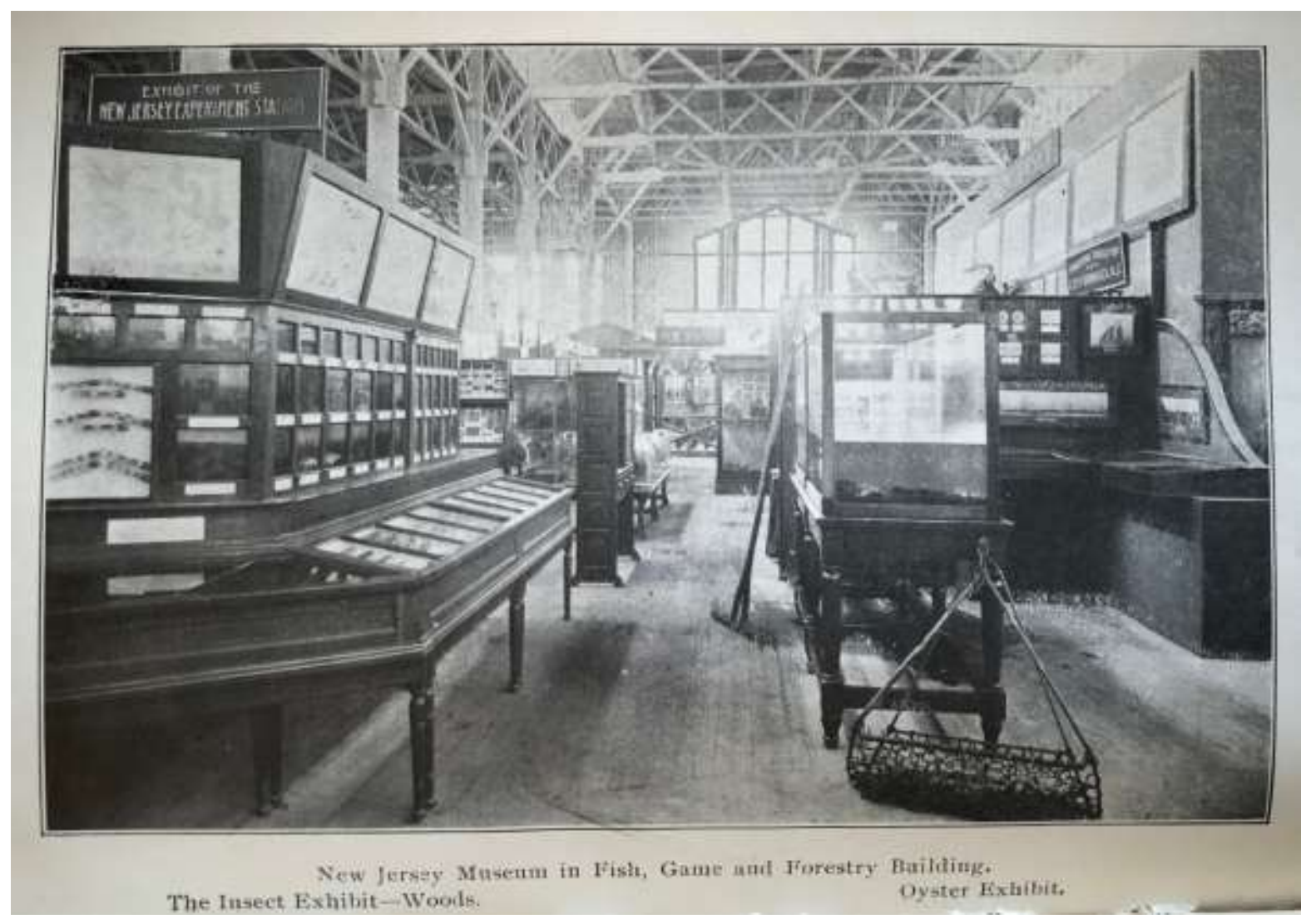

Displays prepared by Dr. John B. Smith for national and international expositions. These displays have been lost to history. ${ }^{26}$

${ }^{26}$ J.B. Smith, "Report of the Entomologist," in Twenty-third Annual Report of the New Jersey State Agricultural Experiment Station and the Fifteenth Annual Report of the New Jersey College Agricultural Experiment Station for the Year ending October 31, 1902 (Trenton, New Jersey: State Printing Office, 1903), 442. 


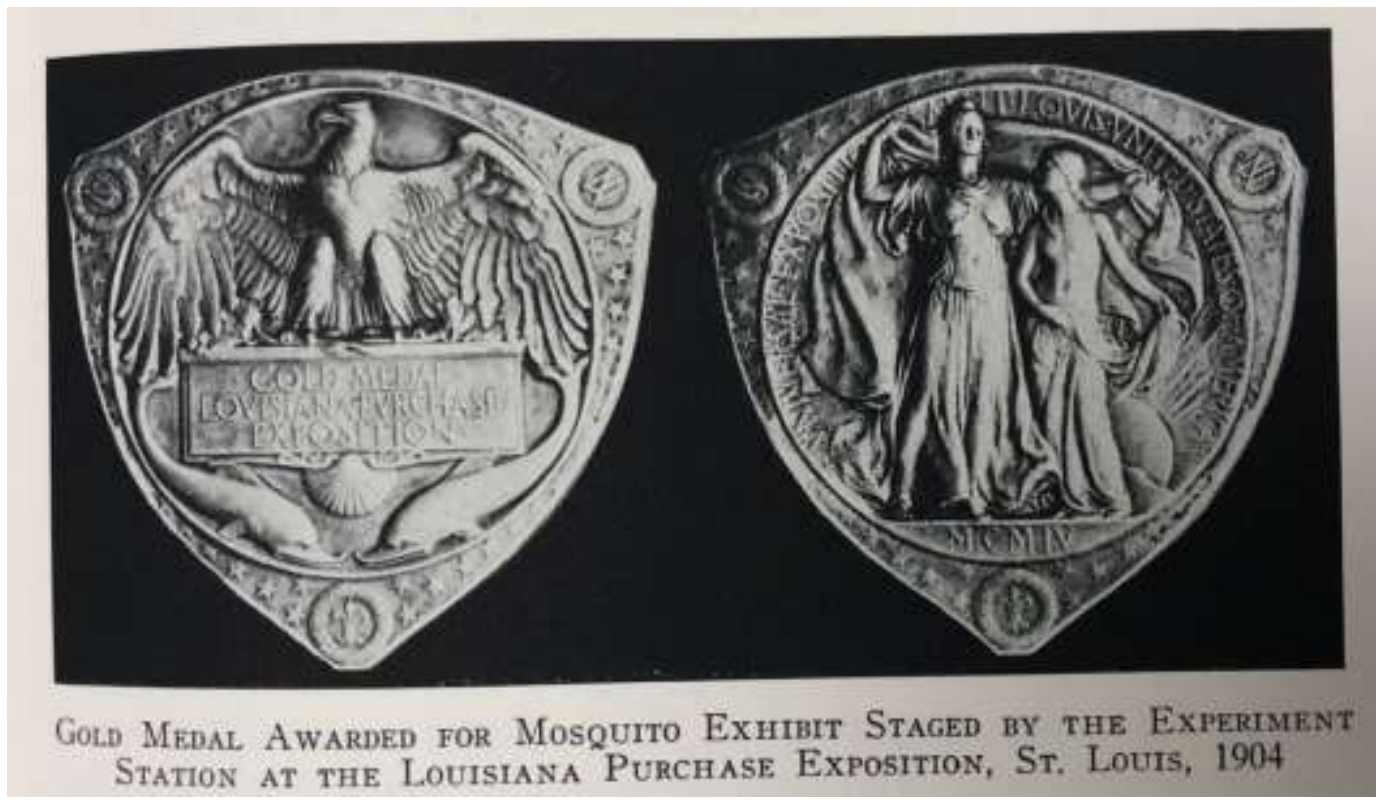

The Gold Medal awarded to the insect collection mosquito exhibit at the 1904 St. Louis Louisiana Purchase Expedition. ${ }^{27}$

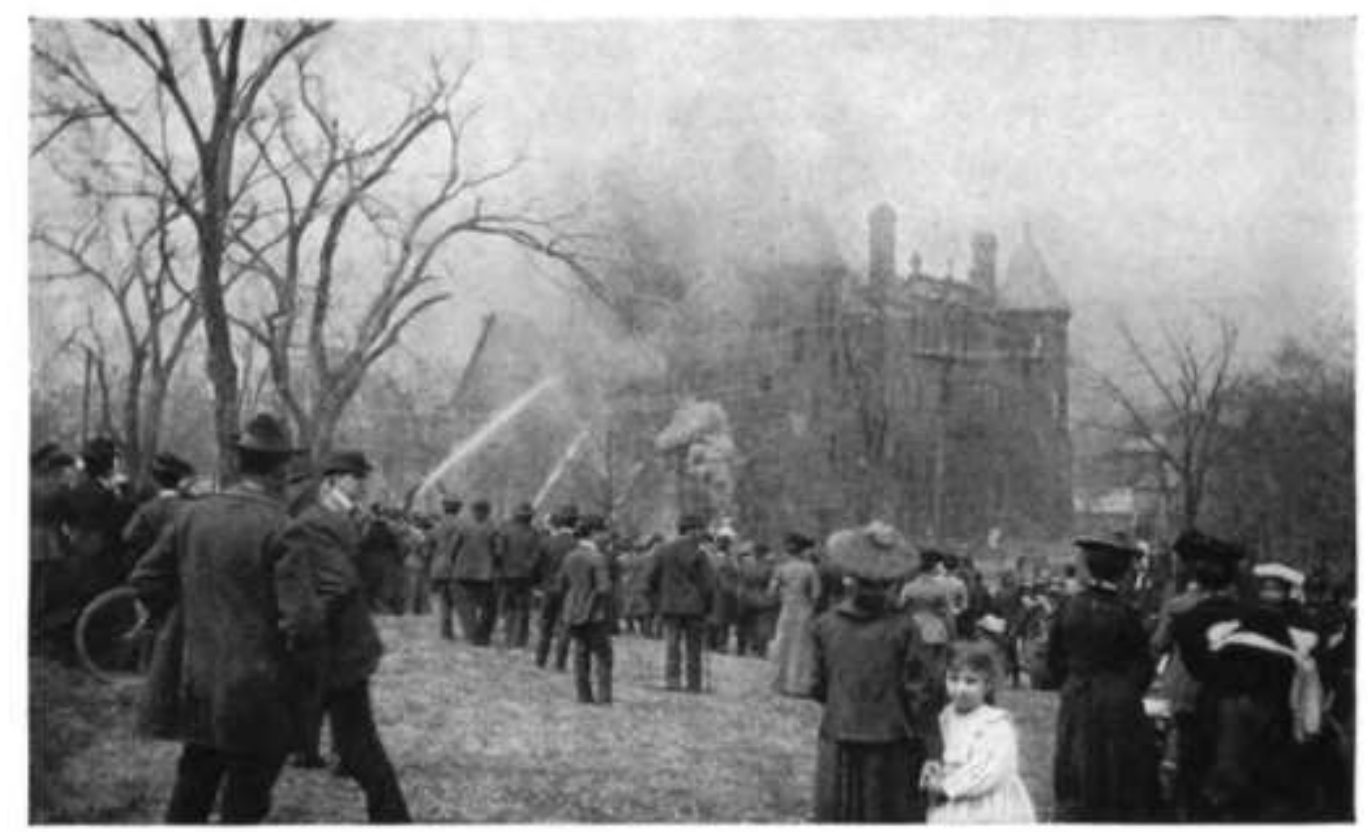

The Burning of New Jersey Hal.t., April. 23, 1903

Photograph of New Jersey Hall burning on April 23, 1903 and the crowds that watched. Photograph used with permission of Rutgers University Special Collections and University Archives.

${ }^{27}$ C.R. Woodward and I. N. Waller, New Jersey's Agricultural Experiment Station 1880-1930 (New Brunswick, New Jersey: New Jersey Agricultural Experiment Station, 1932). 
On the morning of April 23, 1903 a devastating fire broke out in New Jersey Hall. When it burned, it housed classrooms, offices, libraries, equipment, and important biological collections of the Agricultural Experiment Station, including a large portion of the Rutgers Insect Collection as well as plants and parasitic fungi. Despite the raging fire and heavy drenching by water, most of the insect collection was saved as students and faculty repeatedly ventured into the burning building to carry out what they could. A front page article in Rutgers newspaper, The Targum, on April 30, 1903 observed:

Meanwhile all the students had arrived and began the work of removing valuable property. This work was directed by the skilled work of those officers, professors and students who knew the location of valuable property and the best avenues of approach. The chief work was done by the back stairway, which afforded access to all parts of the building not yet in flames.

The saved property was deposited on the grass of Bleecker Place and was properly guarded by a cadet attachment placed by Dr. Scott's order.

As gleaned by THE TARGUM reporters, by interviews with those occupying the various rooms of New Jersey Hall, the following account of salvage and loss is accurate, as far as is now known:

The loss of Professor Smith includes manuscripts, pamphlets, and notes of great scientific value. About two-thirds of the entomological collection was saved by the students and others and is in good condition. The remainder, being also in covered cases, is thought to have been protected from water. More than half of Professor Smith's library was not rescued and it is feared that the loss by water on this is serious.

The most valuable thing in the building was the Hulst collection of butterflies, Dr. Scott personally rescued from the building. He seemed to be in all places at the same time and worked harder than anyone present. ${ }^{28}$

The New Jersey Hall fire also made the front page of the Daily Homes News on April 23, 1903.

Under the heading STUDENTS SAVE COLLECTIONS the following was reported:

From the first, the students devoted their energies in saving the valuable property in the building. Everything was gotten out of Director Voorhees' rooms and

${ }^{28}$ The Targum (New Brunswick, New Jersey), April 30, 1903. 
practically everything from Professor John B. Smith's department, including the collections of mosquitoes and other insects of which he is trying to relieve the state.

The articles carried out by the students were piled on the grass along Bleecker Place, opposite the building. One band of students formed a cordon around the heap until all was out that could be gotten out. Then all hands started to work carrying the articles to Ballentine Gymnasium and storing them there.

General Quincy O'M Gillmore was at the fire and he soon saw that firemen were being hampered by the crowd. He ordered out the cadet corps that was waiting at the gymnasium for drill hour. The cadets in full uniform and with fixed bayonets, marched around and kept the crowd back a respectable distance from the building. ${ }^{29}$

A second article on page 1 of the paper that day was under the heading:

\section{STRANGE CREATURES SAVED FROM THE BURNING BUILDING} Prof. Smith's Mosquitoes, Bugs, Etc., Taken from The General Disaster

The fire at the Experiment Station today, threatened for a time to wipe out the great collection of mosquitoes made last year by Professor of Entomology, John B. Smith, who was made State Entomologist by the recent legislature. The mosquitoes came from all over the State, the Professor having secured a bottle full from each county. After hard work the students and firemen got the mosquitoes safely out. They were afraid if they left them there the bottles would break and the mosquitoes would escape. Other creatures were saved too - great big black beetles with horns, seventeen-year locusts, house-flies, gnats and cockroaches and many other insects from an orthoptera to a gryllus hemipteran, or more plainly speaking, from a katydid to a cricket.

When the collection made its appearance on the outer lawn, it scared the people more than the student's bayonets did. When the creatures were carried across the lawn, it was hard work keeping the masses from running away.

The Hulst collection of moths and butterflies was saved under the personal supervision of President Austin Scott and F. H. Dodge. Mr. Dodge was torn between his desire to take pictures of the scene and a desire to save property. The latter instinct triumphed and the moths were saved, although there is a difference of opinion as to whether Mr. Dodge or President Scott deserves the chief credit.

Anyhow, Professor Smith's collections were saved and although the moths and mosquitoes may have gotten a little mixed up he will be able to go ahead with his work of ridding the state of its pests.

${ }^{29}$ Daily Home News (New Brunswick, New Jersey), April 23, 1903. 
Like with Hulst, Harrison Gray Dyar, Jr. tried to persuade Smith to donate his collection to the United State National Museum, playing on the disastrous fire as a reason. Fortunately, at least for the history of the collection at Rutgers, Smith and Dyar were involved in a legendary feud (at least among the entomological community of the time), regarding, among other things, Smith's belief that Dyar had wrongly criticized his species identifications and published results that were not his to publish. On May 16, 1903, just a few weeks after the fire, Smith responded to a letter by Leland O. Howard, strongly rebuking Dyar and his efforts to secure the Smith and Hulst collections:

Dear Dr. Howard: Thanks for yours of the 14th inst. I have had a communication from Dr. Dyar on another matter, and incidentally he says as follows: "You ought to have put those types in the National collection long ago as I have repeatedly urged before this warning was directed against you. In the next fire you may not fare so well" To that I have answered as follows: "Under conditions as they exist at the present time, not one specimen of either the Hulst or my own collection will go to the National Museum except in direct exchange. If I find it necessary to get a safer place than we have, the insects will be very much more accessible to me at New York City or in Philadelphia. I do not feel that the National Museum has any claims upon me, though up to the present year I have done everything that was within my power to increase its collections in Lepidoptera." 30

A rather astonishing exchange between Smith and Dyar predated this by a few years but may at least help to partly explain why Smith was so adamant about not transferring his collection to Dyar at the American Museum of Natural History. In May, 1901, Smith recounts how Dyar suggested he would destroy specimens to insure his taxonomy was unchallenged. Dyar, then in July, responds to Smith that he was essentially joking and that he takes care of the national collection appropriately. Their acrimonious account follows:

Smith: First, he accepts my identification of impleta with luteicoma in so grudging a spirit that he suggests destroying the type - of impleta, I presume "lest future changes in the synonymy result." It is to be assumed that Dr. Dyar wishes to be taken seriously, and in view of the fact that there are several hundred types in his

\footnotetext{
${ }^{30}$ M.E. Epstein, Moths, Myths \& Mosquitoes. The Eccentric Life of Harrison G. Dyar, Jr. (Oxford: Oxford University Press, 2016), 81.
} 
charge, the suggestion is unpleasant reading. It is a somewhat startling method of securing stability of nomenclature! ${ }^{31}$

Dyar: Prof. Smith's remarks in the May CANADIAN ENTOMOLOGIST contain two separate counts. He implies that I might be led by personal views to an improper treatment of the collection in my charge. This implication I indignantly repudiate, and leave Prof. Smith to explain his breach of etiquette as best he may. While Prof. Smith's lack of humour has led him to misunderstand my views, he has no right to imply that with any personal views whatever I would not properly conserve the National Collection. This collection, rapidly becoming the finest in the country, will continue to be conserved with the greatest care. ${ }^{32}$

Fortunately, despite the fire and the omniscient warning by Dyar in 1903, in what was a prescient decision, the Hulst and Smith collections had been moved to a small fire-proof room in the basement of the newly-constructed Ralph Voorhees Library located just across the courtyard from the Agricultural Experiment Station building. Although reference to when the collection was moved is lacking, as the new building was completed in 1903, it must have been placed in the library within months of the fire. ${ }^{33}$

After the fire Smith continued to raise concerns for the safety of the collection and in the 1904 Report of the Entomological Department of the New Jersey Agricultural Experiment Station noted:

The collections of the Department have been materially increased during the past year by the direct field work of the members of the staff, by the mosquito staff and, to a small extent by purchases of economic series. A summary of the material in the collection was prepared for and at the request of the President of the College, and transmitted to him. The type collections and, in fact, the entire collection of Butterflies and Moths is now housed in a small room in the Ralph Voorhees Library, beyond the danger, it is hoped, of fire and flood. While the present arrangement is a decided improvement upon previous conditions, it is not what is needed and separates the Department from a part of its collections. A fire proof building sufficiently large to house the Entomological Laboratory and its collections is one of the real necessities. It goes without saying that there would be no objection to its housing other Departments as well.

\footnotetext{
${ }^{31}$ J.B. Smith, "Types and Synonymy," The Canadian Entomologist 33, no. 5 (1901): 147.

${ }^{32}$ H.G. Dyar, "Further about the types of Acronycta," The Canadian Entomologist 33, no. 7 (1901): 191.

33 Thirty-ninth Annual Report of Rutgers Scientific School, The State College for the Benefit of Agriculture and the Mechanic Arts (Camden, New Jersey: State Printing Office, 1903), 121; J.P. Wall and H.E. Pickersgill, editors, History of Middlesex County New Jersey 1664-1920 (New York, New York: Lewis Publishing Company, 1921 ), 194.
} 
The reference made to collections in my last report indicated the necessity for a safer housing, and this necessity has been quite forcibly illustrated by the fire already referred to. Owing to the excellent rescue work done by the College students, practically all the collection was saved; but there is considerable damage and a great disarrangement, which has made it unavailable for purposes of study. The station needs a fireproof annex in which the valuable records and collections can be safely placed. ${ }^{34}$

In 1912, shortly before Smith died, the Entomology Department and the collection moved to a converted barn behind New Jersey Hall. It would remain in the Entomology Building until 1938 when the department and the collection would move again to John B. Smith Hall, a converted industrial building on Georges Road in New Brunswick.

The insect collection continued to grow through the work of Smith until his death in 1912. After his death, his wife donated his entire collection to Rutgers and the 1912 report of the Board of Trustees noted, “Mrs. Smith has very generously made a gift to the college of Professor Smith's collection of Lepidoptera and Noctuidae. It is an exceedingly valuable donation; it will bear his name; and, with the Hulst Collection, already owned, will emphasize and strengthen the position of Rutgers as a foremost institution in the richness of such collected treasure, in the facilities for investigation and demonstration in Entomology"35 The following report regarding the vast Hulst and Smith collections was included in the Rutgers College Catalog for 1911-1912:

\footnotetext{
${ }^{34}$ J.B. Smith, Report of the Entomological Department of the New Jersey Agricultural Experiment Station for the Year 1903 (Trenton, New Jersey: State Printing Office, 1904), 564, 585.

${ }^{35}$ The State College for the Benefit of Agricultural and the Mechanic Arts, Forty-Seventh Annual Report (Rutgers Scientific School, 1912), 38.
} 


\section{ENTOMOLOGY}

As part of the equipment for instruction, research, and insect control a large collection of insects has been accumulated. It falls in three groups: the economic, the general systematic, and the special collections.

The economic collection consists of material illustrating the life history and habits of a large number (catalog being prepared) of species of insects that influence in an important way the welfare of mankind. Most of the material is in wooden boxes, measuring about $16 \times 20$ inches with glass covers. The rest of it is included in Riker mounts.

The general systematic collection contains many thousands of species (catalog being prepared) and is stored mainly in Schmidt boxes.

The special collections are the Hulst and the Smith groups:

The Hulst Collection.-The Hulst Collection of Lepidoptera represents the life work in entomology of the Reverend George D. Hulst, PH.D. It consists of two parts: the first, a general collection of butterflies and moths, was presented to the College in 1890 and was received and cared for soon afterward by the Professor of Entomology; the second part, though included in the original gift, was retained by the donor during his lifetime and increased in value by the scientific labor expended on it. This came into the possession of the College in 1901 and contains 1,217 species, of which 549 are types of descriptions written and published by Doctor Hulst, in 3,830 specimens. In the families studied by him this collection is without a peer. Exclusive of these special families there are in the first part 828 species, including twelve types, in 2,775 specimens The entire collection thus contains 2,195 species, 561 types, and 6,605 specimens.

The Smith Collection.-The Smith Collection of Lepidoptera represents the work done by the late Professor John B. Smith during his connection with Rutgers College. The collection is especially rich in the family of noctuid or owlet moths, where at the latest enumeration 1,683 species (348 of them types) were represented by 8,930 specimens, -figures which have been since materially increased. In addition there are numerous unarranged and undescribed species and a large series of species in other families. Altogether there are not less than 2,000 species and over 12,000 specimens.

It is fair to estimate the entire college collection of Lepidoptera included in the Hulst and Smith collections as exceeding 4,200 species and closely approaching 20,000 specimens. Not more than three or four collections in the United States exceed this in scientific value.

1912 Announcement in the Rutgers College Catalog for 1911-1912 describing the Hulst and Smith insect collections. ${ }^{36}$

\footnotetext{
${ }^{36}$ Rutgers College Catalog for 1911-1912 (New Brunswick, New Jersey: Rutgers College, 1912), 235.
} 
Shortly after Smith's death, his longtime lab assistant, E. L. Dickerson, reminisced about Smith working in the Rutgers Insect Collection and offered a personal glimpse of his methods and care:

And, finally, it may not be amiss to briefly describe Professor Smith's method of working. Sunday was the day of all others that was usually selected for the purpose of determining new species and to do whatever else required the consultation of the entire collection.

In the years that I spent at the Experiment Station the collection was kept in a small basement room in the fire-proof college library, and here it was that I frequently spent the Sunday with him, working on the Hulst collection of Geometridae. This was the one day of the seven in the week when Professor Smith found time to discuss things lepidopterological, and in this room I learned much concerning questions of nomenclature, and of old entomologists who left this world before I stepped into the field of entomology.

In naming specimens for collectors, Professor Smith always preferred to place the name on the pin because, he said, there was less danger of confusion. If any doubt arose concerning the identification of a specimen recourse to the collection was immediately made and usually an instant was sufficient to draw a conclusion. If perchance it would turn out to be new only a few minutes more were required to write a description. All types were labelled so at once, not only with the designation "type" or "cotype," but in all cases with the name of the insect as well, so that no question would ever arise as to just what a given specimen was type of. Thus the future student of Professor Smith's collection, though he may find the drawers well crowded, will not be likely to draw the involuntary sigh one usually gives on seeing a type collection with merely the word type on the specimens or even only a type label below a series of specimens. Professor Smith was always careful as to these details and never attempted to gain time by shirking work of this kind. ${ }^{37}$

${ }^{37}$ E. L. Dickerson, "The work of Professor John B. Smith in economic entomology," in Proceedings of the Staten Island Association of Arts and Sciences 4 (1912): 12. 


\section{The Headlee Years (1912-1943)}

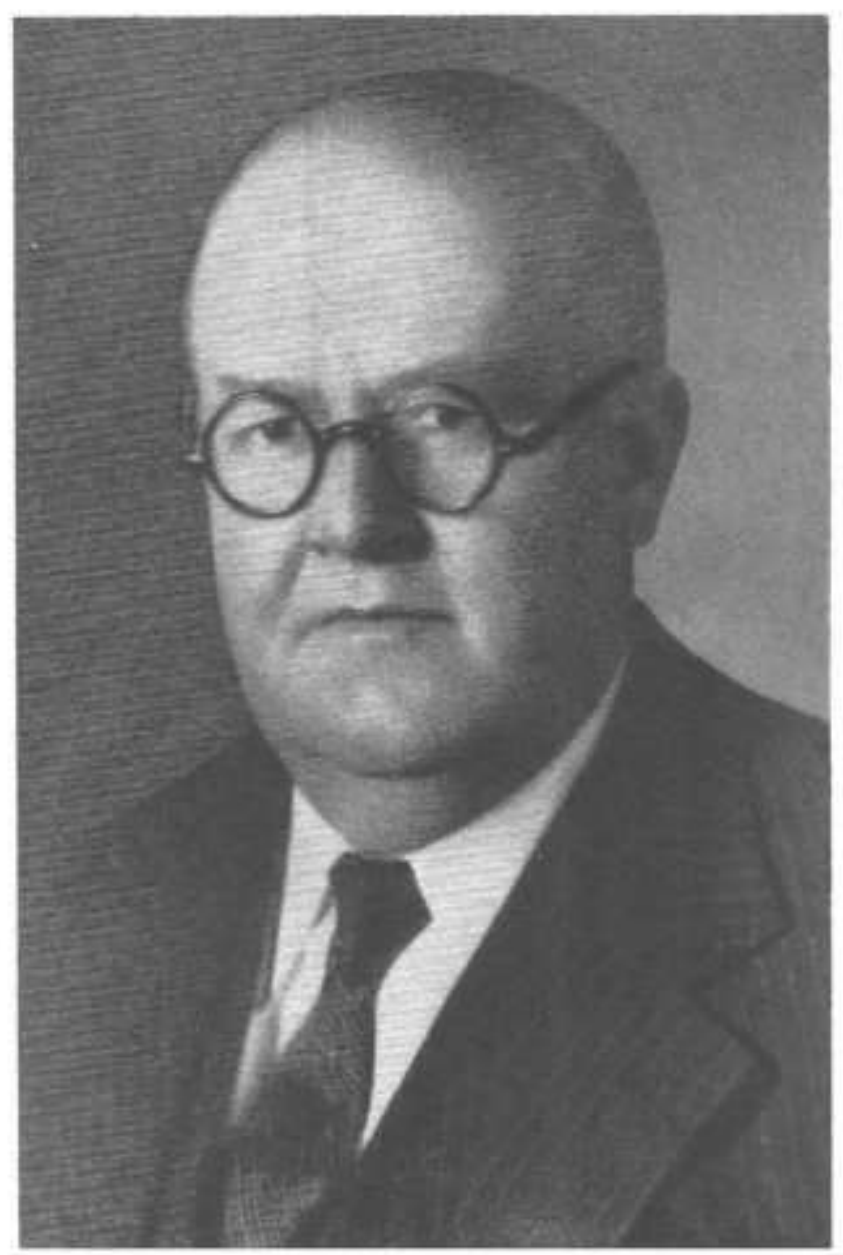

Themas J. Headlee

Dr. Thomas J. Headlee. Photograph courtesy of Rutgers University Special Collections and Archives.

After John B. Smith's death in 1912, Thomas J. Headlee was appointed as the Director of the insect collection. In February of that year, the Entomology Department and the insect collection were moved to a new building renovated from an old barn on Neilson Campus. Early photographs show the stark Entomology building soon after it was converted, and later photographs a venerable older building covered with ivy. 

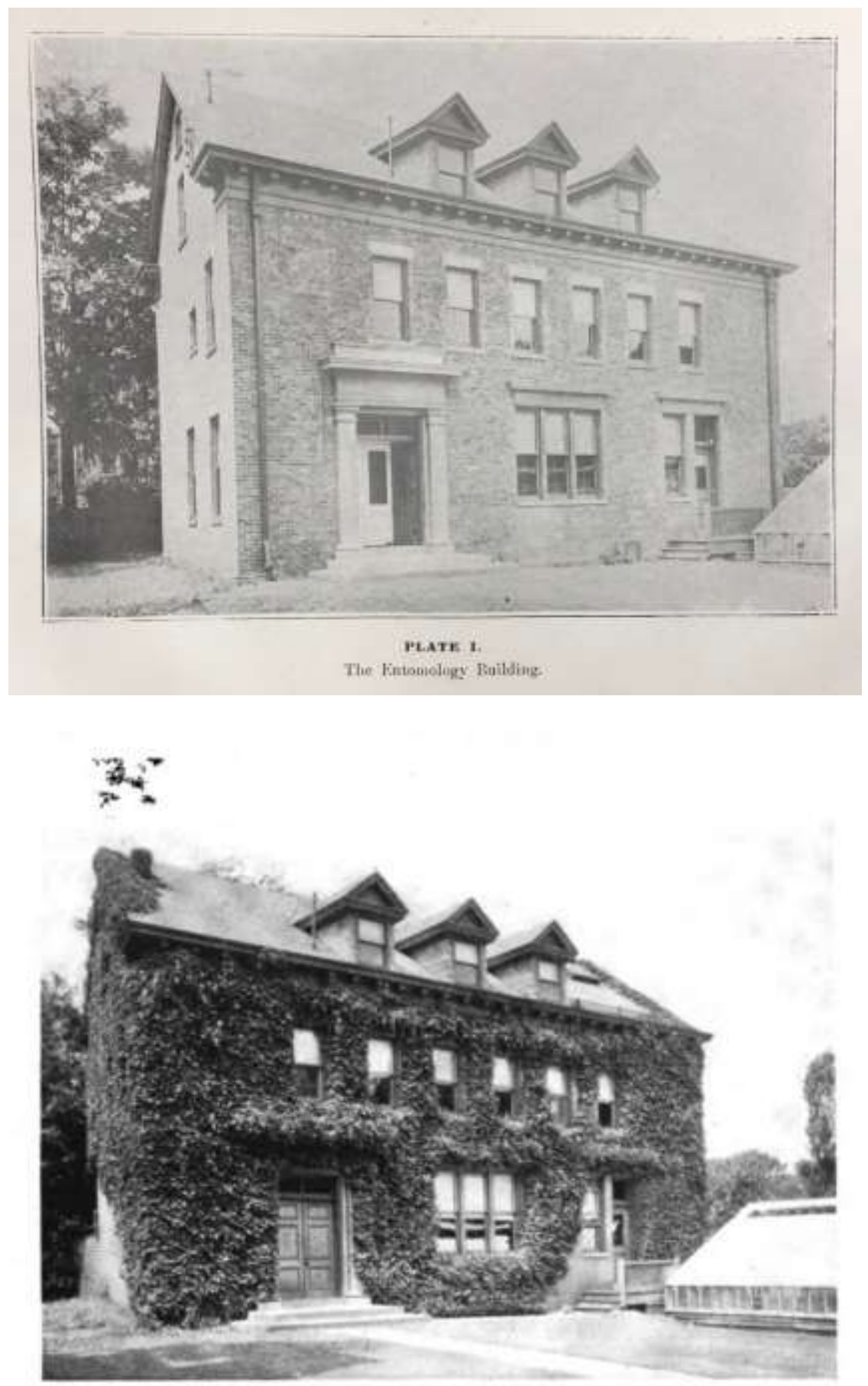

The Extomotogy BuLbing

The Rutgers Entomology Building that housed the insect collection from 1912 to 1937. Photographs courtesy of Rutgers University Special Collections and University Archives. 
The setup apparently was not ideal as the insect collection at the time was described in an unpublished essay by Dr. John B. Schmitt:

All of the collections came to rest on the second floor which was partitioned into three offices and a large central room. The rows of wooden insect cabinets were there to partition off a space for secretaries, a small chemical laboratory, a central passage, and a space for an assistant to Dr. Headlee. ${ }^{38}$

Dr. Headlee served as the Entomology Department Chair until 1943 and during his tenure the insect collection apparently grew slowly. Unlike the Smith years, when the collection featured prominently in annual reports, there was virtually no mention of the collection in annual reports prepared by Headlee. Schmitt also noted "The Experiment Station collection increased slowly during Headlee's tenure, judging by the dates on the specimen date-date location labels." This is not to suggest that Headlee did not have a lasting impact on the collection. In 1921, he hired Carl Ilg as the Department's laboratory assistant in charge of the insects and exhibit materials who "expertly cared for and protected" 39 the collections. In 1930, the status of the insect collection with its vast holdings was described in an article in Entomological News:

Plate V shows the collections as they appear today. They are well kept and in good order. Most of the Noctuidae are in the uniform cabinets to the left in the picture. Someday someone will segregate the type specimens, but whoever does this should know his business, otherwise the collection should be left as it is. There are about 30,000 lepidopterous specimens altogether. Aside from Smith's material there are about 100,000 mounted specimens in all orders in the Department's collection as follows: 35,000 Coleoptera; 14,000 Hymenoptera; 4000 Hemiptera; 4000 Diptera; 1400 Orthoptera and representatives in other Orders in proportion. Although no new types have been added of late years, there is always that hope. However, the bulk of the collection is gradually increasing in size. ${ }^{40}$

\footnotetext{
38 J.B. Schmitt, “A History of the Insect Collections at Rutgers University, 1879-1979,” Rutgers.edu, 28 June 2019, https://entomology.rutgers.edu/museum/history.html.

${ }^{39}$ Ibid.

${ }^{40}$ J.D. Gunder, “North American Institutions Featuring Lepidoptera,” Entomological News 41, no. 2 (1930): $31-33$.
} 


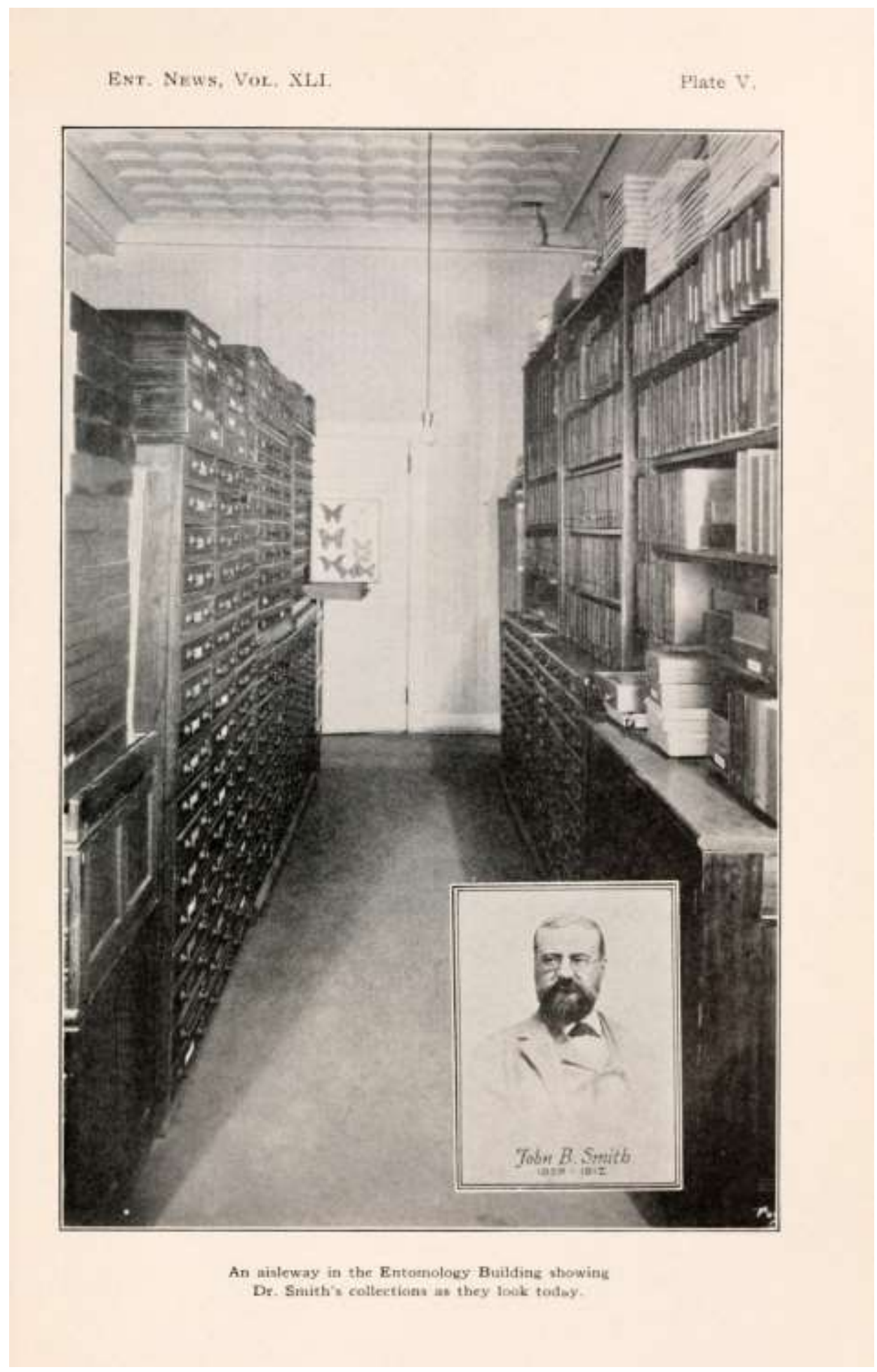

The insect collection in the Entomology Building as shown in the 1930 Entomological News. ${ }^{41}$

${ }^{41}$ Ibid. 


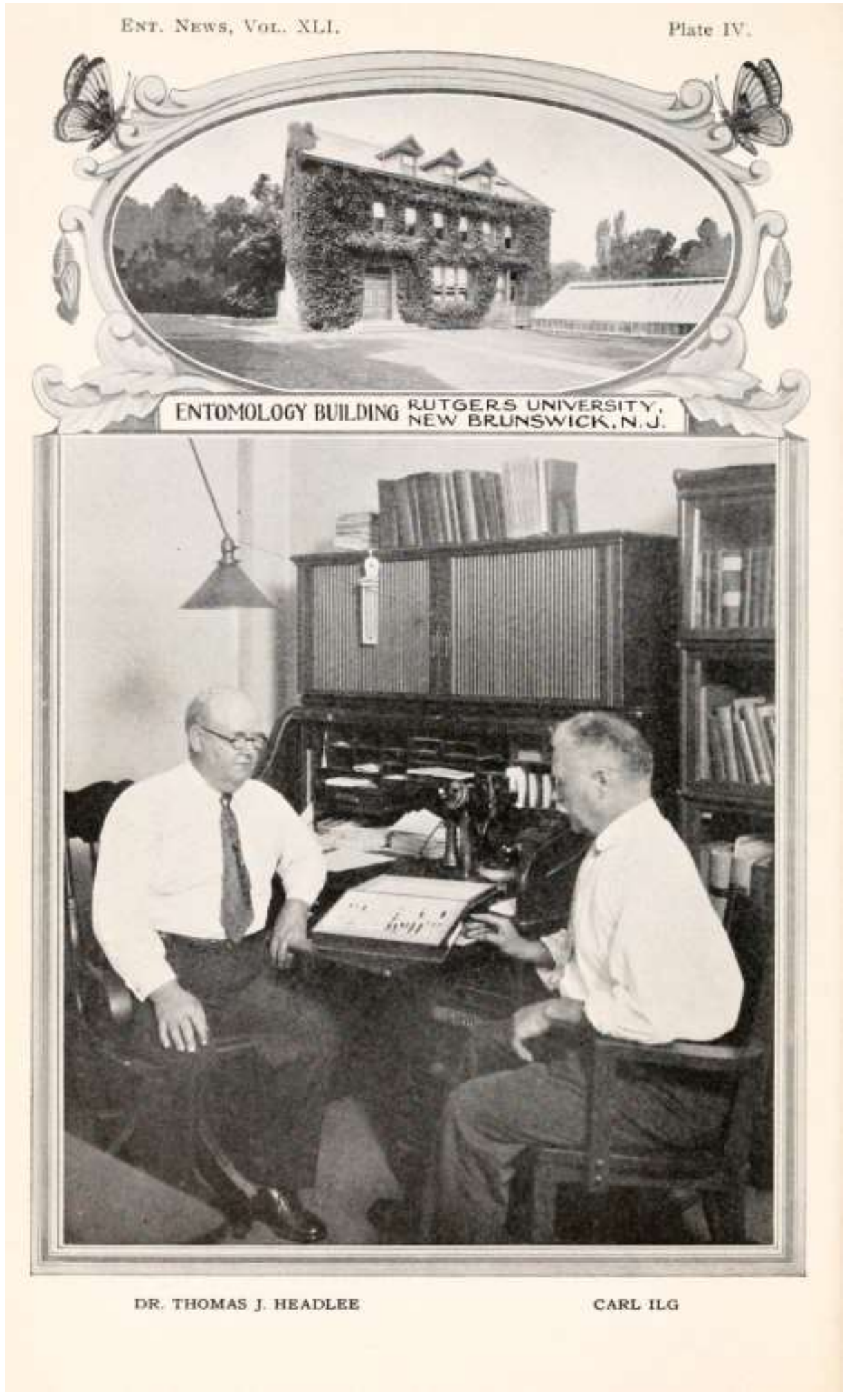

Dr. Thomas Headlee and Mr. Carl Ilg, curator and assistant curator of the insect collection as shown in the 1930 Entomological News. ${ }^{42}$

${ }^{42}$ Ibid. 
In 1937, the Entomology Department and the insect collection moved once again to a converted industrial building on Georges Road that would eventually be named John B. Smith Hall. The collection would remain there for another 65 years. A fascinating description of the building and the collection comes from Dr. Schmitt's essay:

During the summer of 1937, the entire Department of Entomology moved to its present location on Georges Road. The building given to Entomology had been the offices and part of the manufacturing facilities of "Reckitt's Blue", a supplier of bluing preparation used in washing clothes. The building was remodeled for our use by the Works Progress Administration (a "New Deal" Agency) following plans worked out by the late Professor D. Manley Jobbins. Included in those plans was a large room to be used exclusively as the Insect Museum. For the first time in their history, the Rutgers collections were to be housed together in the security of a separate room.

The Insect Museum was located along the front of the first floor of the present building, in space now subdivided into three offices and a hallway. The large cabinets of glass-topped drawers were arranged along a back wall; the Schmitt boxes were placed on steel shelving, and a work and office space was provided for me at one end. The security originally planned was lost however, because the museum also had to serve as a hallway, the alternative route passing through two classrooms and two laboratories. Everybody went through the museum, but at least the building was relatively fire proof.

In 1943, the late Dr. Baily B. Pepper became Department Chairman. Dr. Pepper was very appreciative of the importance of the collections, and tried to provide better security for the Smith and Hulst collections by having a system of enclosing doors on tracks built around the cabinets. The doors were provided with hasps and the arrangement looked very secure. Unfortunately, the doors in the back row were soon found to be easily lifted off the track and pushed aside, and the whole arrangement was rather troublesome. ${ }^{43}$

Schmitt continued describing the collection in his essay:

The Rutgers' collections at that time consisted of the following:

(1) A general collection known as the "State Experiment Station Collection" which had been begun by Smith. It was stored in Schmitt boxes and was especially strong in Coleoptera.

(2) The Hulst collection of Lepidoptera

43 J.B. Schmitt, “A History of the Insect Collections at Rutgers University, 1879-1979," Rutgers.edu, 28 June 2019, https://entomology.rutgers.edu/museum/history.html. 
(3) The Smith collection of Lepidoptera. These single collections had been combined into a single collection stored in large glass-topped cases (See Photo 1.) Together they contained over 32,000 specimens, representing almost 6,000 species. The most important feature was the presence of over 2,200 type specimens, largely those of Smith and Hulst.

(4) The Boerner Collection of Coleoptera. This fine collection had been purchased sometime prior to 1936 from the estate of an amateur in Philadelphia (I was told by Mr. Ilg). It was stored in about 20 large "book-form" boxes (so-called because when closed and arranged on edge, they resembled large volumes).

\section{Transfer of the Hulst and Smith Collections to the American Museum of Natural History}

Despite the new location for the collection, Dr. Schmitt became concerned about the utility and condition of the Hulst and Smith collections. This concern would in turn lead to large changes in the collection, including the transfer of the Hulst and Smith collection to the American Museum of Natural History. Schmitt noted in his essay:

For one thing, all of those type specimens made the entire collection too valuable taxonomically to be used as a service collection for making comparisons. Surely only a taxonomic specialist should be permitted to handle a type, yet the types were jeopardized every time the collection was used for comparison. Also, all the specimens were by then so old and faded in some groups, determinations of species by comparison were often of doubtful validity. Apart from the prestige Rutgers enjoyed as the repository of the Smith and Hulst collections, therefore, there was very little value to us in the possession of the collections.

I finally presented these viewpoints to Dr. Pepper and was encouraged to inquire at the American Museum of Natural History and elsewhere to see what might be worked out. The final result was an offer from the American Museum of Natural History to take the Smith and Hulst collections and to provide us with a synoptic collection of fresh specimens of North American Lepidoptera, with the current taxonomic designations.

The significance of the Hulst and Smith collections cannot be overstated. Although the transfer to the American Museum of Natural History was a loss to the Rutgers collection, the legacy of the extensive work of Reverend Hulst and John B. Smith while at Rutgers was now protected. An announcement in the Journal of the Lepidopterists' Society noted the importance of the collection 
and the holdings ${ }^{44}$ and it was described in a Bulletin of the American Museum of Natural History

as:

ONE OF THE MOST IMPORTANT ADDITIONS to the collection of the Department of Insects and Spiders of the American Museum of Natural History was the accession of the J. B. Smith and G. D. Hulst collections of Lepidoptera. These collections were donated by the Department of Entomology at Rutgers University, and the transfer was made possible through the generous cooperation of Dr. William H. Martin, Dean of the College of Agriculture, and Profs. Bailey B. Pepper and John B. Schmitt of the Department of Entomology of that institution. Combined, this acquisition represents one of the most valuable collections of North American Lepidoptera in existence, as it consists of 32,022 specimens, representing almost 6000 species, and over 2200 type specimens, including approximately 1200 holotypes. The majority of the type specimens are those of Smith and Hulst. ${ }^{45}$

While the collections were praised, some of the work of both Smith and Hulst regarding the

labelling of specimens in the collection was criticized with respect to type specimens and locality

information. The entry provides a glimpse into the way they both worked the Rutgers collection:

Unfortunately, a number of the early workers were not careful to list specifically the locality of the type, as compared with the remainder of the type series, and this has never been so listed in the literature. It was not uncommon to find a list of localities from four or six states, for example, following a description, with no indication at all of what was considered the type locality. A rather confusing situation in the light of present-day population studies can result, as exact localities are needed to pinpoint subspecific population names. The present paper should help solve many of the problems, as Smith in particular was guilty of this procedure. However, he did have his type series labeled as to "male type," "female type," and "cotypes." It is assumed that his "male type" is equivalent to the more modern term "holotype," with the "female type" representing the "allotype." However, these two terms are not used in the text of the paper unless they specifically appear on the type labels. The only exception to Smith's labels stating "male type," "female type," and "cotype" was his very early work, where every specimen in the series was merely labeled "type." At this time he usually used black-bordered labels, as opposed to his later use of red-bordered labels with the improved terminology. The type specimens of Hulst present more of a problem, as this author was notorious for his method of labeling type specimens. Very often the locality as given in the original description does not agree with that on the label on the specimen, or the locality as given in a subsequent paper by the same author. In addition, Hulst had the habit of labeling specimens as "type" when he was doing identification work,

\footnotetext{
${ }^{44}$ F.H. Rindge, "Smith and Hulst Collections," Journal of the Lepidopterists' Society, 8 (1954): 46.

${ }^{45}$ F.H. Rindge, "The Type Material in the J. B. Smith and G. D. Hulst Collections of Lepidoptera in the American Museum of Natural History," Bulletin of the American Museum of Natural History, 106, no. 2 (1955): 172.
} 
apparently using this word in the sense that the specimen was typical or like the type. In this manner, one sometimes finds four or six specimens labeled "type," while the original description states that the species was described from a single example. Needless to say, this greatly complicates matters with regard to the Hulst types, and considerable care should be exercised when one is dealing with these specimens.

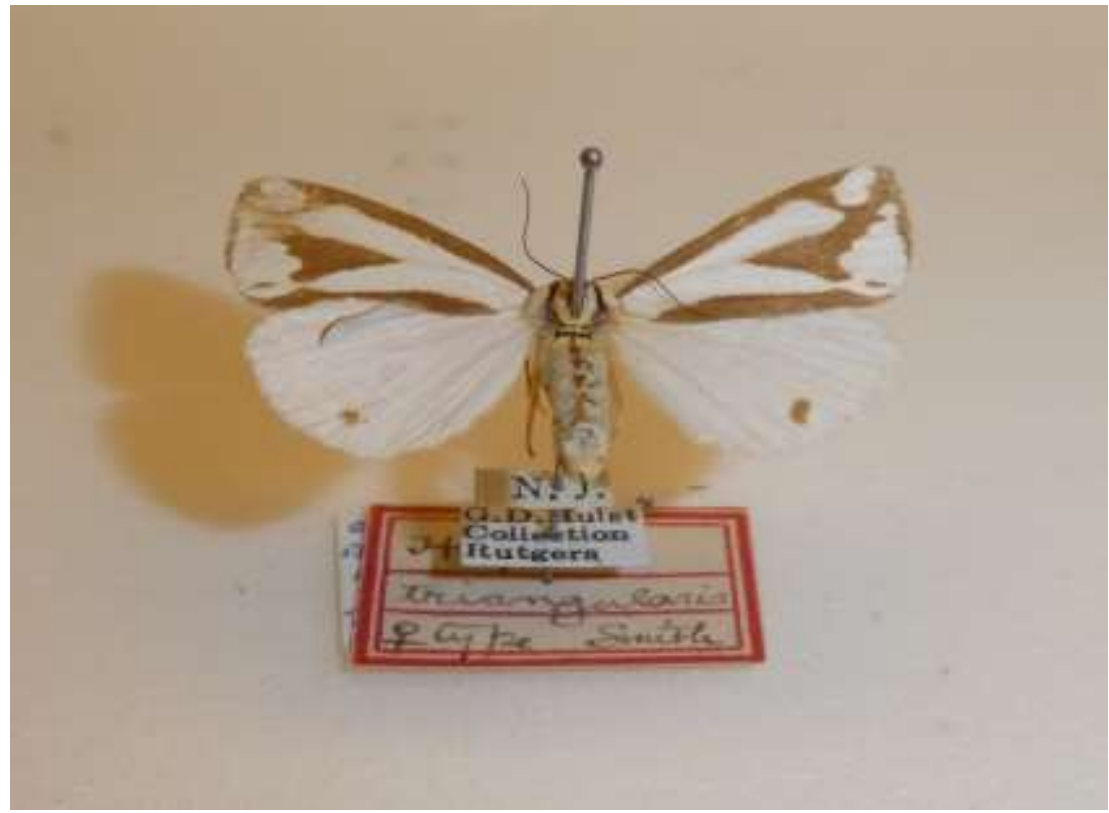

Hulst and Smith Type Specimens from the Hulst and Smith collection transferred by Rutgers University to the American Museum of Natural History in 1953. Personal collection of the author.

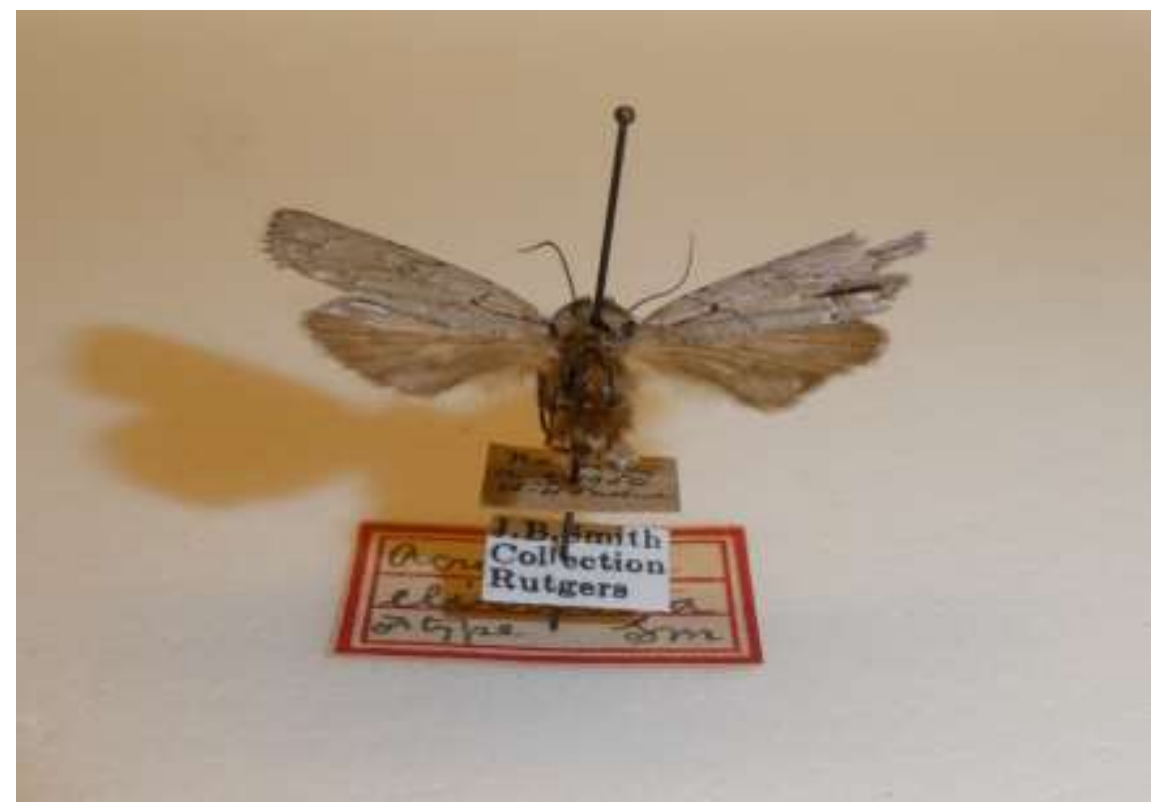




\author{
SMITH AND HELST COLIFCTIONS OBTAINED \\ BY AMERICAN MUSELIM OF NATLRAL HSTORY
}

\begin{abstract}
The Department of Insects and Spiders of the American Museum of Natural History proudly angounces the acoession of the JOHN B SMIrI and GEORGiE D. Hunst collections of lepidoptera. This valuable accession was made possible through the cooperation of Dr. Whilisu H. MAKrin, Dean of the College of Apriculture, and Pro-

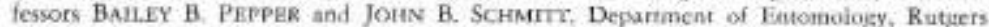
University. This is one of the most valuable collections of North American Lepidoptera in existence, as it consists of 32,022 specimens representing almost 6,800 species. It contains over 2200 type specimens includiog approximately 1200 bolocypes. The Inxiority of these type specimens are thuse of SMITH and HULST, who were the outstanding uuthorities on the North American Phalsenialac (Noctuida). Geometrida, and Pyralidae of their generation. There is a small amount of type material of coher acuhors.

JoHN B SMtral (1858-1912) came to Rutgets in 1889, after spendinit the precoding three yean at the United States National Museum, and tenained there until his death. Hro was the Statr Entomologist of New lersey from 1894 uatil 1912. SmmTr built up the North American Phalacnid collection at Rurgers until it was one of the lest collections in this family in existence. As be was the leadiag wuthority on this family, he also teceived material for idencification from diffetent collectors, and thus more interesting specimens came to hand. SMTrH described a very large numbet of new species, and he publishod a frear number of pajers. These include not only papers with the oripinal descriptions of new species, but it number of generic revisions and check lists. The collection at Rutgers formed the basis for the majocity of these, and hence its great value.

Georcen D. Huss (1846-1900), while describing a number of Thalaenids, is better kanwn for his work on the Genmetridx and Pyalidx. The HLIST col lestion is one of both butterflies and moths, bat is richest in his specialties. He published almost one hundfed papers, mostly on descriptions of early srages and of new species of Lepidoptera. Included in this liat of publications were revisions of the Noteh Ametion Epipaschiino, Phycitida, and Geometridie, which still stand as the basic works in these groups. Tbese japers were hased mainily on his collection, which was piven to Ratyeers and contains many cyjes.
\end{abstract}

Every specimen in these collecticas is bbeied with the original I. B. SMTH or G. D. HuLsT colliecrica labels, or is being so labeled before beine incorpofated into the Lepidoptera collection of the American Muscum of Natural History, In this way. furute workets can recognize the specimens from these collections. 'The primary types are beinit segrejated into the type collection at the American Museum, and it list of all rype material is being prepared. An identified collection of Lepilaptera is being depenited in the Department of Entomology of Rutgers University.

FMRDMKICK H. RINIKGE, Associate Curator, Dept. of Insects and Spiders, American Maseum of Natural Hiscory, New York 2A, N. Y, Ii, S. A.

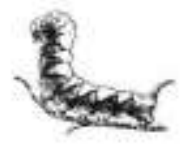

Announcement in the Journal of the Lepidopterists' Society for the transfer of the Hulst and Smith insect collections to the American Museum of Natural History. ${ }^{46}$

${ }^{46}$ F.H. Rindge, "Smith and Hulst Collections," Journal of the Lepidopterists' Society, 8 (1954): 46. 


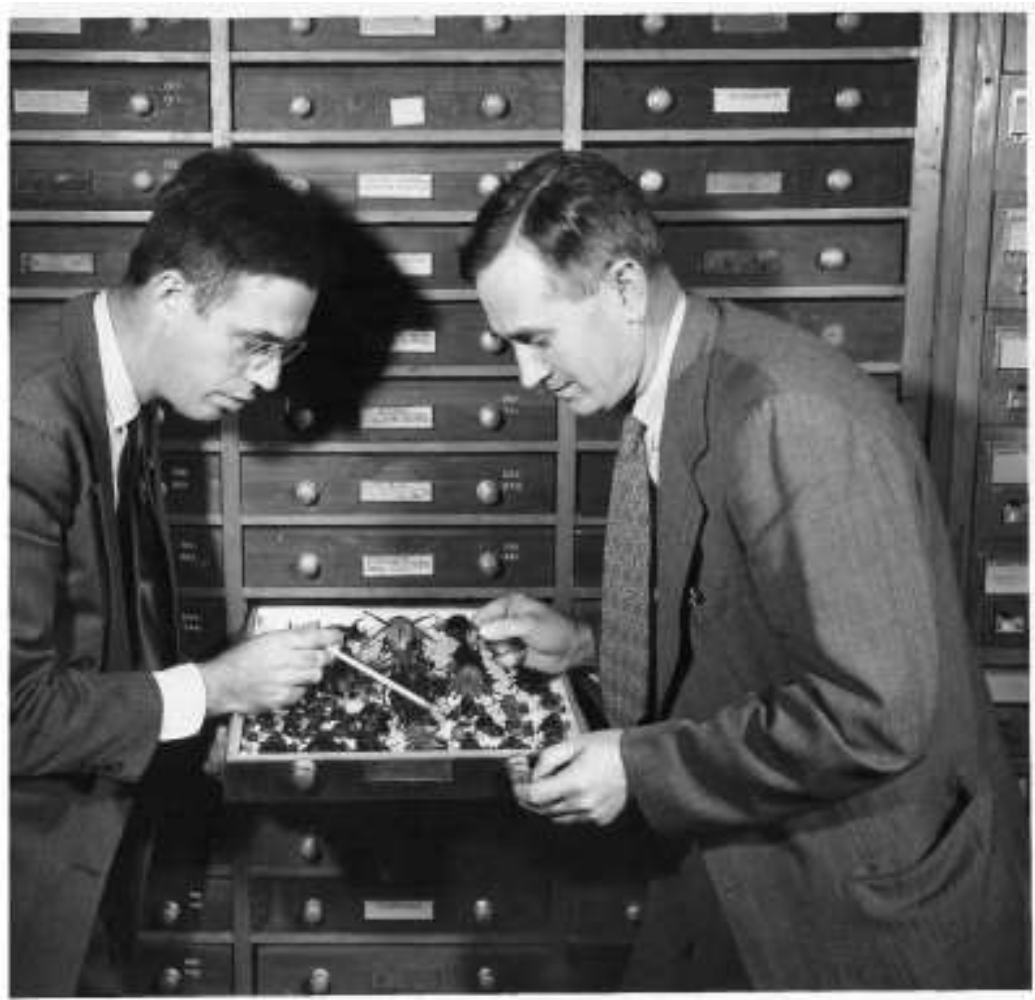

Photograph, left, dated 10/46/1949 with Dr. Bailey B. Pepper (right) and Dr. John Schmitt (left) examining specimens in the wooden glasstopped drawers that housed the insect collection. Used with permission of the Rutgers Department of Entomology.

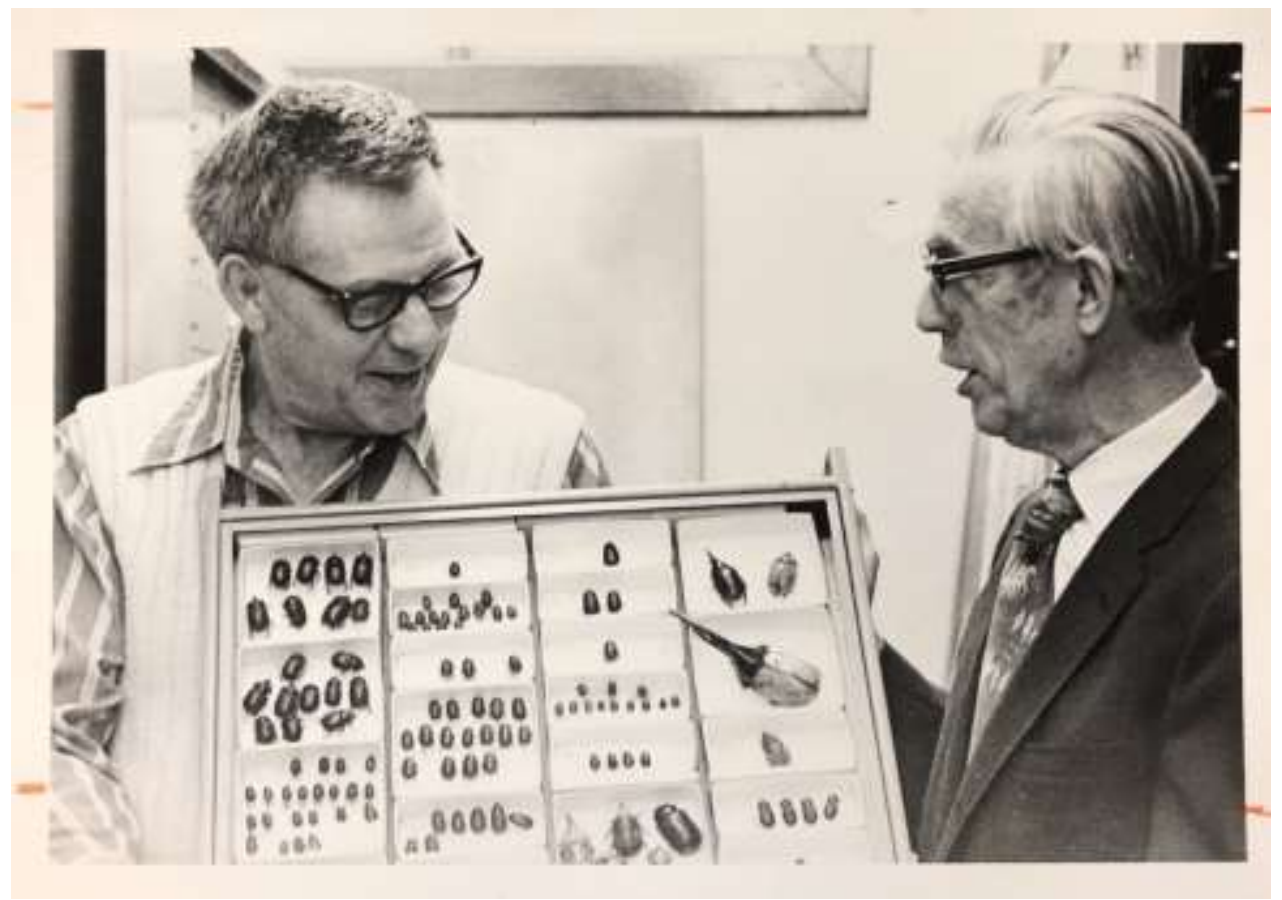

Photograph of Dr. John P. Reed (left) and Dr. John Schmitt (right) examining imported beetle specimens from the insect collection. Undated but circa 1976. Photo courtesy of Rutgers University Special Collections and University Archives. 


\section{The Pepper and Schmitt Years - Transfers and Growth (1943-1976)}

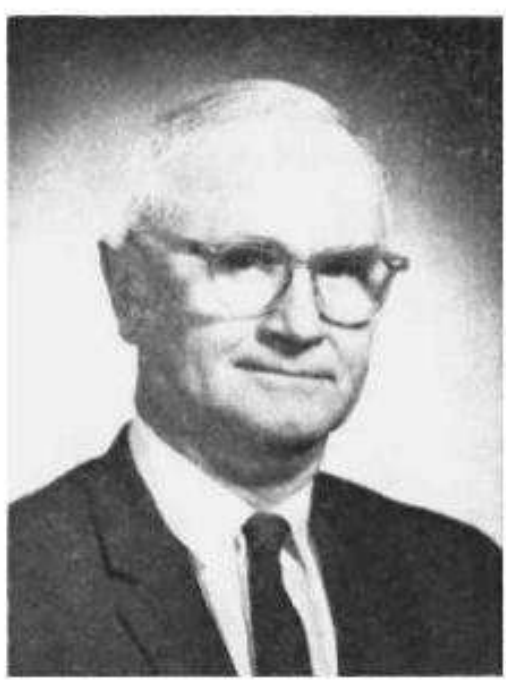

BAH.EY B. PEPEEK

Photograph courtesy of the Rutgers University Department of Entomology.

In 1943, Dr. Headlee retired and Dr. Bailey B. Pepper became Chairman of the Entomology Department. The importance of the Rutgers Insect collection was embraced by Dr. Pepper and he was instrumental in modernizing the collection. Dr. Schmitt described these efforts:

In completing this discussion of the modernizing of the museum facilities, I find it difficult to restrain my expression of appreciation of the late Dr. Baily B. Pepper. From the time he became Department Chairman, he showed his support for the importance of the collections. In his modernizing effort, he found, over a period of three years, funds for the purchase of 14 cabinets of 40 drawers each, and 8 cabinets of 28 drawers each, together with the very large number of pinning trays, separators, name block, etc. needed in the transfer. When it became clear that help would have to be employed in the transfer, Dr. Pepper again found the funds to employ that help, right up to the typing of the card catalogue. It was indeed an expression to Dr. Pepper's faith in the department that the collections were in such excellent shape in $1965 .{ }^{47}$

The Headlee and Pepper years also saw the collection grow with the acquisition of a number of important collections and the efforts of the Entomology Department:

In an effort to build up a good reference collection of immediate and practical use to the entomologist, an effort which has received particular emphasis during the last fifteen or twenty years, the Borner collection of Coleoptera, the George W. Barber collection, and the Comstock collection of butterflies of New Jersey have been acquired. The collections of Tabanidae and bees have been greatly expanded through the efforts of Elton J. Hansens and Robert S. Filmer, respectively. The number of specimens preserved in alcohol has also been increased and a new, simpler method of storage instituted. Until 1952 the museum had far too few insects, such as fleas and lice, mounted on slides, but since then, Hansens and Paul Burbutis have prepared and identified several hundred slides of fleas for the

\footnotetext{
${ }^{47}$ J.B. Schmitt, “A History of the Insect Collections at Rutgers University, 1879-1979," Rutgers.edu, 28 June 2019,
} https://entomology.rutgers.edu/museum/history.html. 
collection. A quantity of other parasitic insect and mite material is now under preparation. ${ }^{48}$

During his tenure as Chairman, Dr. Pepper also planned and oversaw the insect collection being moved to the second floor of John B. Smith Hall and into new cabinets specially designed for insect collection storage and protection. Unfortunately, the very large steel cabinets did not fit through the stairwells and they had to be lifted by crane in 1958 through the building windows after they had been removed:

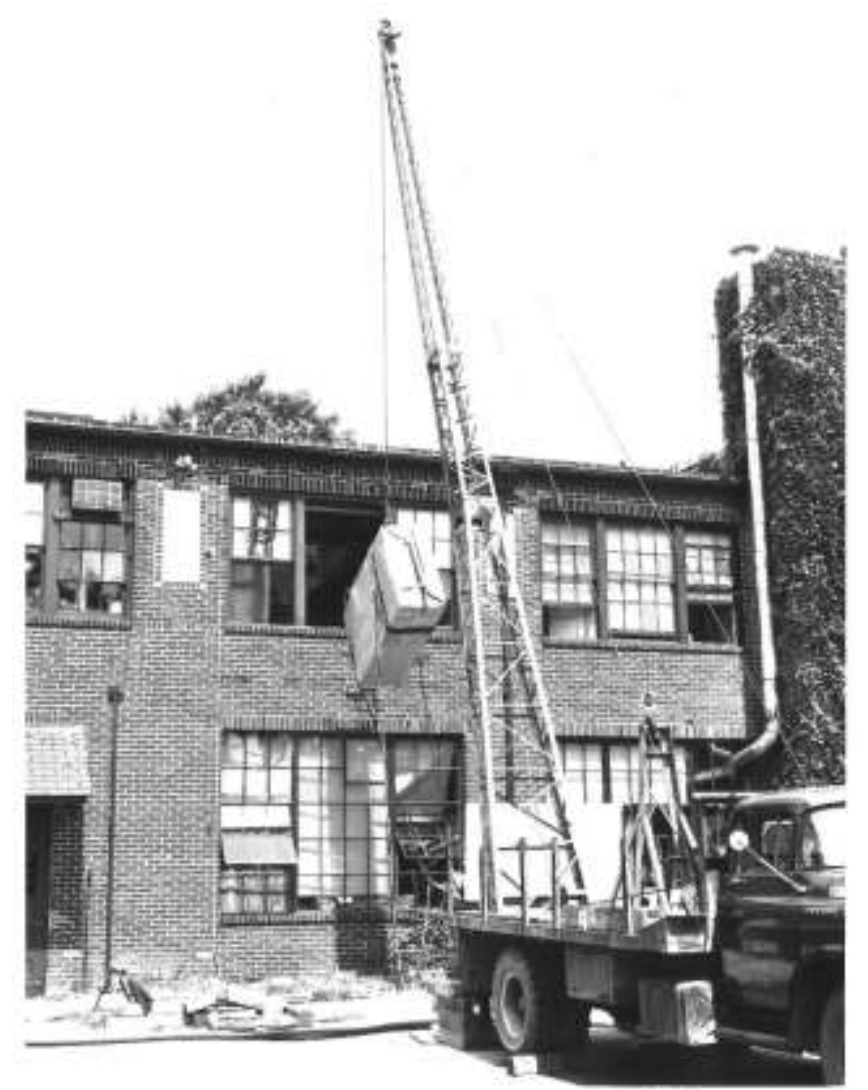

Photograph of the new insect storage cabinets being lifted by crane into John B. Smith Hall in 1958. Used with permission of the Rutgers Department of Entomology.
In planning this move, the reduction in floor space for the collections brought attention to the motley assembly of storage boxes and cases which still housed the collections. In fact, most of them dated back more than fifty years. It was decided that as fast as Dr. Pepper could obtain the money, we would buy modern steel cabinets, relying upon residual insecticides to control dermestid beetles so destructive to collections, and get rid of the old "tight-lock" boxes of drawers.

The loss of space also dictated that these new cabinets should be as tall as we could obtain, and so the first lot finally arrived in the summer of 1958. To our dismay, we found that the new cabinets could not be carried up either stairway of the Entomology building. It was necessary to employ a crane operator to have them lifted through the second floor window. ${ }^{49}$

\footnotetext{
${ }^{48}$ E.J. Hansens and H. B. Weiss, Entomology in New Jersey (New Brunswick, New Jersey: New Jersey Agricultural Experiment Station, Rutgers State University, 1954).

${ }^{49}$ J.B. Schmitt, “A History of the Insect Collections at Rutgers University, 1879-1979,” Rutgers.edu, 28 June 2019 , https://entomology.rutgers.edu/museum/history.html.
} 
For the next twenty years, the collection continued to grow in utility and was rearranged and reorganized to reflect advances in taxonomy. In 1961, Dr. Donald R. Whitehead, at the time, a Rutgers undergraduate student, undertook the initial reorganization, combining the two large Coleoptera collections into one and rearranging all of the other insect orders except the Hymenoptera. ${ }^{50}$ For the remaining order, the reorganization of this part of the collection was described:

Our Hymenoptera were transferred and completely reorganized by another student whose chief interest is the Hymenoptera. He was Dr. Charles Porter, then a graduate student at Harvard, and now, I believe, on the faculty at Fordham. Two summers were spent on this exacting work, and again we have the satisfaction of having our collection worked over by a specialist. ${ }^{51}$

The status of the collection and the extensive reorganization work was also provided in a 1961 report:

Those of our former students who remember our insect museum as a collection of assorted wooden boxes and cases, stained and faded to dull colors, and tagged with a nondescript assortment of labels, would be most pleasantly surprised by a visit to our renovated museum. Thru a program initiated three years ago, most of the pre1900 wooden equipment has been replaced with high-quality steel cabinets and roller-drawers, fitted with Plexiglass covers. The tray system is being used for all orders except Lepidoptera.

Transfer and reorganization of our collections is admittedly a tedious and timeconsuming task and at the present time is about two-thirds completed. All of the Lepidoptera, both the Ringe and the Comstock collections have been transferred, and a card catalog to them completed. Our Coleoptera has been completely transferred, and about half of the material reorganized by our former student Don Whitehead, now Lt. Whitehead at Edgewood Arsenal. Our Hymenoptera have been transferred and completely reorganized by Charles Porter, a student at Harvard, and an accomplished hymenopterist. A card catalogue of our Hymenoptera is now in the making. ${ }^{52}$

\footnotetext{
${ }^{50}$ J.B. Schmitt, “A History of the Insect Collections at Rutgers University, 1879-1979," Rutgers.edu, 28 June 2019, https://entomology.rutgers.edu/museum/history.html.

51 Ibid.

${ }^{52}$ Entogeny (New Brunswick, New Jersey: Department of Entomology, Rutgers University, 1961).
} 
Other efforts made at the same time included the development of a "cross-indexed card catalogue of all species in the major orders was prepared to facilitate the use of the museum." ${ }^{53}$ Over the next few years the collection continued to grow, albeit slowly, with important additions of flies and moths:

The most noteworthy were some excellent series of Tabanid Flies contributed by Dr. Elton J. Hansens. Then about 1970, the late Dr. John P. Reed began to provide a large number of fine specimens of Lepidoptera (exclusive of the butterflies). His specimens were most meticulously spread and prepared, and also added to the collection many new species to our New Jersey list. Those fine specimens now in the collection area testimony to Dr. Reed's love of Entomology.

With the growth and reorganization of the collection, space was once again a problem. We are again fortunate to have Dr. Schmitt's essay to eloquently describe the situation:

However, the museum was indeed cramped for space. The tall columns of steel cases gave the room a depressing "Mausoleum" look, and moreover, the room provided only a single small table for work space. Any future expansion was truly impossible, and it seemed unlikely that students would find much interest in such a confined space. With Dr. Reed working almost daily in the museum, our space needs became desperate.

When the Nematology program vacated Room 206 adjoining the museum, I saw a great opportunity. Following a conference with the Chairman, Dr. B. R. Wilson, I circulated a final "Curator's Report" to the faculty, detailing the nature of the problem, and asking that Room 206 be added to the museum facilities. I further proposed that a doorway be broken through between the two rooms. Fortunately, the faculty approved the addition to the museum. ${ }^{54}$

In 1973, the curator noted some of the strengths and weaknesses of the collection and raised the first concerns about university support (concerns which would ultimately require the intervention of a State Senator to help save the collection thirty years later). They wrote, "Our objective has been primarily to assemble 'identification' or 'comparison' collections of the insects of eastern United States, especially the middle Atlantic region. It must be admitted that our

\footnotetext{
${ }^{53}$ Ibid.

${ }^{54}$ Ibid.
} 
materials in Coleoptera, Lepidoptera and Hymenoptera are decidedly more complete than our representation of most other orders. Our greatest weakness is the absence of a collection of insect larvae. We have about 140,000 pinned specimens." ${ }^{255}$ The report continued to describe the extensive efforts at cataloging the collection:

In the orders Lepidoptera, Coleoptera, and Hymenoptera, all species in the collection may be located by a card catalogue. Each species is represented in the appropriate order catalogue by at least two cards. One of these lists the genus first, followed by the "specific" name; the second gives the "specific" name first. The purpose of this second card is to provide a means of finding a zoological species in which the generic name has been changed. In this case, a third card, resembling the first, but using the "new" generic name has been prepared, with appropriate entries on the first two. There also appears on the card the number of the cabinet and tray in which the species is stored. Cards to nominal species "sunk" in synonomy are retained in the catalogue, but with appropriate entries and cross-reference to the valid name.

We have considerable material in various major orders, but badly in need of revision and rearranging...The most active part of the collections is the Lepidoptera, to which Dr. John Reed has been adding extensively through is black light collections. Material in Tabanidae and Culicidae is also being added but our Diptera is not extensive. ...However, with no University financial support for curating, the care of the collections has had to be a squeezed-time operation, whenever teaching and other primary duties permit."

\section{Changing Times - Utility, Organization and Building Neglect (1976 - 2002)}

During the latter part of the century, the insect collection saw a succession of curators. The collection continued to be reorganized and to grow but with a refocused emphasis on a teaching collection rather than a depository of type material. In 1976, the annual curator's report noted that "We have about 200,000 pinned specimens," and that the "Insect Museum is on a progression to become one of the better regionalized insect reference collections at universities on the east coast" ${ }^{56}$ In 1977, the annual curator's report noted that "After many years of effort, appointment of a taxonomist-ecologist was achieved and the Insect Museum is receiving the attention it needs

\footnotetext{
${ }^{55}$ Entogeny (New Brunswick, New Jersey: Department of Entomology, Rutgers University, 1973).

${ }^{56}$ Entogeny (New Brunswick, New Jersey: Department of Entomology, Rutgers University, 1976).
} 
as the only reference and study collection in the state. This basic research and teaching tool is rapidly increasing." ${ }^{57}$ In 1984, the curator noted that the Entomology Department and the facilities were "geographically isolated," a problem that continues to the present with the separation of the insect collection from the Entomology Department located in Thompson Hall on Cook Campus. The purpose of the collection was noted by the curator, G. W. Wolfe as "1) provides a resource of reference standards, 2) documents distributional data, 3) facilitates taxonomic and systematic research, and 4) serves teaching activities. The museum also serves as a repository for voucher specimens associated with ecological, parasitic, environmental and agricultural research."58 The report also mentioned that "Research and acquisition of material are actively pursued primarily in the following groups: Coleoptera (primarily Dytiscidae and Curculionidae), aculeate Hymenoptera and, Odonata."

The 1984 report also provided a detailed overview of the "Goals" of the Insect Museum:

The museum is a laboratory and the essential reason for its existence is to foster taxonomic and systematic research thereby contributing to the department's national and international visibility. Therefore, taxonomic and systematic research and the incumbent tasks of collecting and curating are the principal activities in the museum.

Despite being accessed by limited researchers in the late 1980s and early 1990s, the collection and the room it was housed in were described as "well-lit, ventilated, and the collections were maintained pest-free." ${ }^{59}$ In 1989, the final year the annual curator's report was prepared, Dr. Wolfe discussed the potential relocation of the collection to a new building designed to house all of the various biological collections of the University. ${ }^{60}$ Remarkably, this proposal continues to be

\footnotetext{
57 Entogeny (New Brunswick, New Jersey: Department of Entomology, Rutgers University, 1977).

${ }^{58}$ Entogeny (New Brunswick, New Jersey: Department of Entomology, Rutgers University, 1984).

${ }^{59}$ John Michalski, email message to author, February 28, 2019.

${ }^{60}$ Entogeny (New Brunswick, New Jersey: Department of Entomology, Rutgers University, 1989).
} 
explored thirty years later. ${ }^{61}$ Professor Smith, and those that followed, would certainly have appreciated the tone of the curator with respect to the uncertainty of housing the collection and its value:

The Entomology Museum will remain in Smith Hall for an undetermined length of time after the Department's move to Blake. Space has been identified in the meteorology building (a separate building just behind new Blake) to house the museum, but renovations of this area have been long delayed. Further complicating the question of a site for the Entomological Museum, is a rumored proposal to develop a combined "collections facility" to be developed at some point in the future. The "collections facility" would house other biological collections (e.g. herbarium) in addition to the Entomology Museum in a location separate from the Department.

The insect museum at Rutgers is a valuable resource. It houses approximately 250,000 pinned specimens, a moderately sized university museum. We specialize in the insects of New Jersey. This is particularly important because of New Jersey's Pine Barrens, a unique habitat that is the home of many species of restricted distribution. The museum is under the direction of Karl Kjer. Kjer recognizes the importance of preserving this museum, and is currently adding to its collection of Trichoptera. However, we do not have the personnel to expand the museum. Our proximity to the Smithsonian, The American Museum of Natural History and the Philadelphia Academy of Natural Sciences gives our students access to these world class museums. For this reason we do not see the Rutgers insect museum as a major depository of type material, and we are not attempting to compete with these institutions. However, we can house a museum with a very large representation of New Jersey insects, and we can teach our students the basics of museum curation. And by maintaining contact with these major nearby museums, we should be able to attract systematists for occasional visits to our facility. Finally, Kjer plans to develop ties to the agricultural community through contacts with personnel in the county extension offices. In addition, he plans to put together the pest identification collection located in a separate area of the museum. ${ }^{62}$

\section{A New Beginning - The Collection Saved a Second Time (2003)}

Fast forward almost 100 years from the fire in New Jersey Hall to 2002, and once again the collection was threatened, this time not by fire, but by deplorable conditions. Through time and neglect J. B. Smith Hall had fallen into such a state of disrepair and was so unsafe that it was

\footnotetext{
${ }^{61}$ Lisa Reed, email message to author, February 26, 2019.

${ }^{62}$ Entogeny (New Brunswick, New Jersey: Department of Entomology, Rutgers University, 1989).
} 
uncertain whether the collection could be removed from the building. There were rumors that the University planned on demolishing the building with the insect collection still inside. Conditions in John B. Smith Hall were described in a letter to New Jersey State Senator Bob Smith as threatening both the collection and the safety of anyone entering the building:

The collection is housed in J. B. Smith Hall; the northern portion of the building closed because of unsafe conditions. In the collection room, the ceilings are falling and the floor is rotted. Water stains are evident, temperature controls are nonexistent, fire suppression systems are lacking, and squirrels have chewed a hole in a wooden window frame and can move freely in and out of the building.

Insect collections are extremely sensitive to disturbance and poor environmental conditions, and once affected, are unrepairable. The conditions in the building have deteriorated to the point that the collection has been moved into three separate rooms, each with different and unregulated environmental conditions, no fire control systems, and no security. Without immediate attention, the Rutgers Insect Collection will be irreparably damaged. ${ }^{63}$

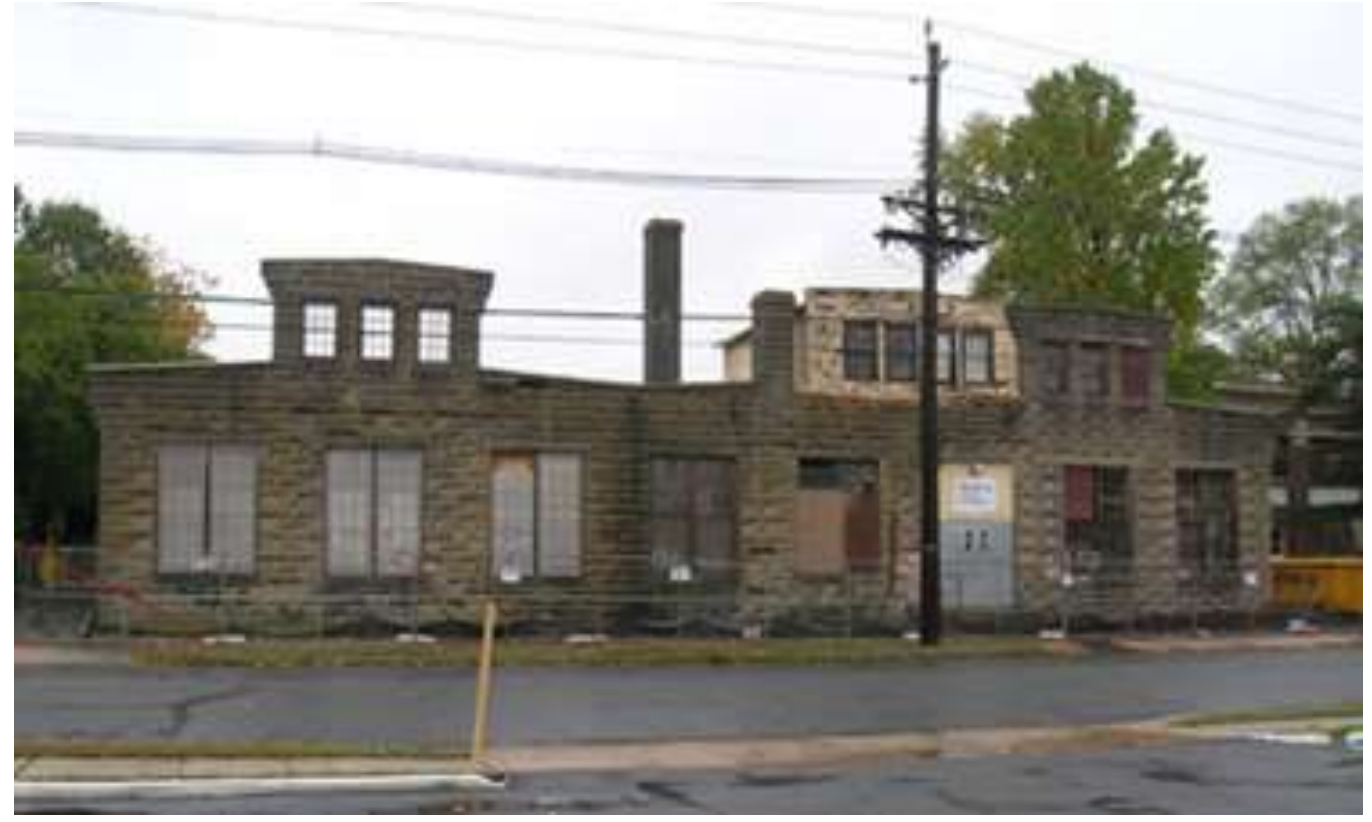

Photograph of the north wing of John B. Smith Hall shortly after the insect collection was removed in 2003. Photo retrieved from rutgersrarities.com on February 26, 2019.

${ }^{63}$ D. Moskowitz, letter to Senator Bob Smith, November 1, 2002. 
Fortunately, in 2003, like in 1903, the collection was once again rescued. After being given a tour of the collection by entomology Professor Dr. Michael M. May in late 2002, the author alerted Senator Bob Smith, a Rutgers University graduate (M.S. Environmental Science 1973) of the situation. Senator Smith quickly began a series of discussions with then University President Richard McCormick in an effort to save the collection. After a number of conversations, correspondence and meetings, the importance of the collection and its roots to the University was recognized. With the collection now saved, an exchange of space negotiated by curator Dr. Carle was accepted by Dr. Brattsten (Chair of Entomology) and Dr. Grassle (Chair of Marine Sciences). In the agreement the Entomology Department exchanged unused space on the top floor of Old Blake for space in McLean Labs where the Entomology Insect collection was to be relocated. Modification of the space for the collection was minor and included the removal of a small wall, new carpeting, painting, and the relocation of a fan switch. A layout designed by Dr. Carle for the insect cabinets was approved by Drs. Brattsten and Kjer with the modification that a walkway should be added through the middle row of cabinets. ${ }^{64}$ The collection now resides in the basement of the McLean Laboratory building. Although far from ideal due to limited space to work, the McLean Laboratories location has temperature controls, a fire suppression system, and security and the collection is safely protected from environmental damage.

Echoing 100 years earlier, Rutgers entomology students were actively involved in the effort to save the collection. Although this time they were not running into a burning building, they petitioned the University President to save the collection in an email signed by the students in the Graduate program in Entomology:

\footnotetext{
${ }^{64}$ An anonymous reviewer provided this information on June 26, 2019.
} 


\section{Dear President McCormick:}

We are students in the Graduate Program in Entomology, and are writing to ask your help in preserving the Rutgers Entomology Museum and associated teaching labs at Cook College. We are offering to help relocate the museum to the first floor of McLean Laboratories, which is next door to our departmental teaching laboratories and Headlee Mosquito Research Labs. The advantages of relocating the Museum to McLean Hall are many, and have been outlined in the attached email. The primary impediment to relocating the Rutgers Entomology Museum to McLean is that Dr. Grassle of the Institute of Marine and Coastal Sciences is warehousing unused furniture in the space. Our faculty have exhausted the administrative avenues on Cook College for acquiring this space and using it as a productive facility. The Museum is presently located in J. B. Smith Hall, which is scheduled for demolition; the current plan is to relocate environmental chambers from Smith Hall to our classroom building, preventing its future use as a teaching lab. In addition, no permanent solution has been proposed for the Entomology collection. The Museum's collection contains over 200,000 insects, which have been collected and curated over the 130-year history of the Entomology Department, many of which have tremendous scientific and historical value. This museum is an important resource, not only for the students, staff, and faculty at Rutgers, but for the people we serve in New Jersey, and for entomologists and researchers throughout the world. Other solutions have been suggested for the Entomology Museum, such as temporarily locating it to the Douglass Biology Building or into temporary trailers. Locating the Museum in the Douglass Biology Building would separate the collection from its primary user group, make routine maintenance and usage difficult. Temporary moves or rental trailers would incur unnecessary expenses at a time when we are all seeking to economize and use our budgets as efficiently as possible. ${ }^{65}$

On October 14, 2003, the collection was moved from John B. Smith Hall to the new location

in McLean Laboratories, an extensive and complicated effort coordinated by the collection curators, Dr. Frank Carle and Dr. Karl Kjer. Just like fifty-five years before, when the new cabinets had to be lifted by crane through a window into John B. Smith Hall, the cabinets and the collection had to be removed the same way. To make the move easier and to avoid damage to the collection, the drawers were labelled, removed from the cabinets, and stacked in specially built racks for

\footnotetext{
${ }^{65}$ Students in the Rutgers Graduate Program in Entomology, email to Richard L. McCormick, April 30, 2003.
} 
transport across the parking lot to McLean Laboratories. The moving company personnel then moved each empty cabinet into place in McLean Laboratories and Entomology staff carried the insect drawers into the building and set them in the cabinets in proper order. Things were going smoothly until:

While Drs. May and Carle moved the last large cabinet to McLean a strong smell of natural gas was noticed as the dolly rolled over a particular section of sidewalk. After the smell was noticed a few more times Dr. Carle alerted the authorities and asked a nearby gas company worker to check for gas leaks. Two fire trucks and several city and campus police cars quickly showed up and it was decided that it was a false alarm until the gas company worker yelled out, "100\% gas right here, everyone out of the area!" The gas line was dug up and found to have 12 penny sized holes where the protective coating had been scraped off during construction. Perhaps the Insect collection had been spared from a blazing end once again. ${ }^{66}$
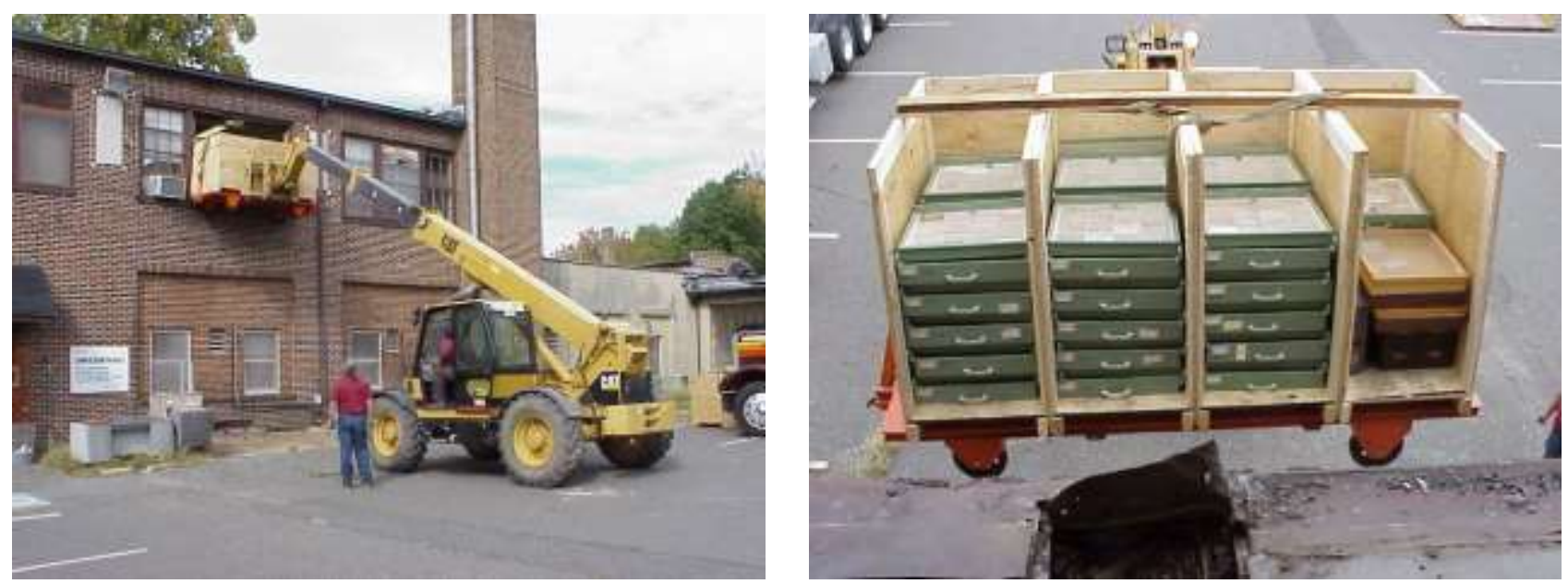

Photographs of the insect collection being removed from J. B. Smith Hall and transferred to McLean Laboratories. Photographs courtesy of Dr. Lisa Reed.

The correspondence between Senator Bob Smith, Rutgers University President Robert McCormick, and others that led to the relocation of the collection illustrates the challenges facing many insect and other biological collections in the United States and around the world including a

\footnotetext{
${ }^{66}$ An anonymous peer reviewer provided this information on June 26, 2019.
} 
lack of funding, space and an understanding of the importance of biological collections ${ }^{67}$ A sample of this correspondence follows:

\section{EcolSciences, Inc.

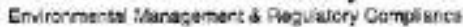

November 1,2002

Senitor Bob Situth

Via fax: (732) $752-7997$

216 Stelton Road, Suito 31

Piseatawsy, New Jersey 08854

Dear Bob:

Thask you for taking the time to talk with me about the Rutgers losect Collection. The collection contains more than 200,000 specimens. It is the largest and most comprehensive collection of New Jersey inseots in the world. It was started before the curn of the $20^{4}$ eentury gnd houses the collections of great entomologis:s, Rutgers alumni, and Ruttgers professon, who entruated the University with the preservation of their specimess. Mary of these individuais were pillars of science in their fields and at Rutgers t.jniversity including Suith, Headlee, Comatook, and Davis, to name just a few. Their accomplishments in entonology had qest repereussions ca insect diserse control and agriculivial production not just in New Jersey, but also throughout the world.

Unfortunately, and nlmost unbelievibly, this geat collaction is in grave and fmminent danger of being destroyed by neglect. I recently visited the collection with Dr. Michael Mry of the Rutgers Entomalogy department and was shocked by the deploribie enditions. The collection is housed. in J. B. Smith Fall; the nortbern pertion of the building olosed bevasse of unsafe coaditions, In the collection room, the ceilings aro faling and the floor is rotted. Waver stains are evident, temperature controls are non-existent, fire suppression systems are lacking, and squirrels bave chewod a hoie in a wooden window frame sad can move freely it and out of the byil ding.

Irsect collections are extremely sensitive to disturbance and poor envirommeatal conditions, and once affested, are unrepairable. The conditions in the building have deteriorated to the point that the collection has been moved into three sepurate rastno, each with different and uriegulated environmental conditions, no fire control systems, and no seourity. Wittrout immediate attention. the Rutgers Insect Colleation will be irreparebly comaged. The collection is an ireplacesble fibrary of the biodiversity of our state and is in immediate nect of cere. The protection of the sollection should not only be of concarn to the University, but to the state as woll. Much moce than just is simigle insect collection, it is a Rutgers and a New Jersey treasure, and its legacy must be preserved.

I appreciate your willingeness to look into this matter. Please do not hesitate to call me if you have any questions or would libe to visit the collection.

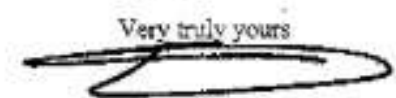

David P. Moskowitz:

Vice President

Ce: Dr. Miehael May, Rutgers Entomology Department

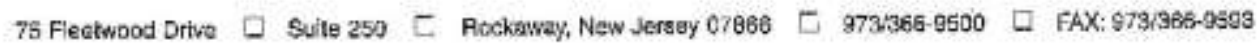

67 "ESA Statement on the Importance of Insect Collections," Entomological Society of America, 6 March 2019, https://www.entsoc.org/esa-statement-importance-insect-collections. 


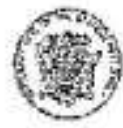

BOD SMITH

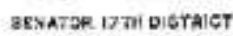

21A STRTTOK Roxn, Surza E-5

PISCASAFAY. NJ OBgsa

(702] 7 5e.0770

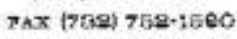

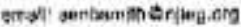

Naw Jeasey Semate RECEIVED

NOV 192002

ECOLSCIENCES, INC.

Joxcrant

Hyviromint:

President-designate Richard McCormick

Rutgers, The State University of New Jersey

Old Queen's, College Avenue Campus

83 Somerset Ŝtreet

New Brunswick, NJ 08901

Dear President MeCormick:

Please allow me to take this opportumity to eongratulate you on your recent appointment as Rutgers' '19th President! As a Rutgers alumni and Piscataway resident, I am very excited that someone of your 3iature. with strong roots at Rutgers and within the local communiry, will be taking the helm of our flagship state university.

Recently, a constituent contacted me regarding the current condition of the Rutgers Insect Colloction, loceted in J.B. Smith Hell at the Department of Entomology. This collection of more than 200,000 specimeos, one of the largest and most comprehensive coliection of Now Jersey issects in the world, is in ErRve danger of being irreparably damaged.

Apparently, the collection room is in a state of dangerous disrepair, with a rotted ceiling and floor, water stains on the walls, and a lack of any fire suppression system and temperature centrols The colloction represents the work and accomplishments of the great Rutgers antomologists who have had a pivotal impact on insect diseage control and agricultural production not just in Ness Jersey, but tiroughout the world. It is a state treasure that should be properly maincained and protected.

I roclize that of the many important issues facing your new administration, this may not seem a high pricrity. However, I believe thas properly preserving New Jersey's history, especially the many accomplishments carried out right here at Rutgers University, is an impertant gosl. I would like to work with you and your staff in securing the appropriare resources to stors and maintain this collection in a safe and accessibje location.

Thank you for your attention to this metter. I an looking forward to working with you over the coming years in ensuring that Rutgers Univaraity continues to be the jewsi of New Jersey's system of public higher education and joins the ranks of the great public research universities.

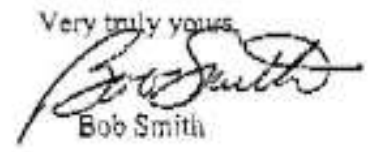


Dec. 0.2002 10:03AM

... $\%$

The Honorable Bob Sinith

216 Stelton Road, Suite B-5

Piscataway, New Jersey 08854

Deat Senator Serith:

It was a great pleagure to have lunch with you and Ellen last Monday and to thank you for your atrong support for Rutgers. Please assure Ellec that I am corminted to giving Piscataway equal recogsition with New Brunswick as a host community for our great state university!

I aloo sincerely thank you for your kind words about my appointment as President of Rutgers, The State University of New Jersey. I am honored to serve the people of New Jeriey in this capsoity and look forward to working closely with you and the rest of our elected lesdership to elevate the status of our stato's Aagship university to the very highest levels of exoellonce, service to our rcaidents, and recogrtition among our peer institutions.

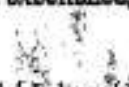

During our lunch you raised the matter of Rutgers' commitment to affurdubif houdifig in Piscateway. Thavo now leamed from Joanne Jackson, Sericor Vice Preaideat and Treakuref that tha Rutgers Master Plan is nearly completed and the proposal will recommend the integratipn of a college town development within the Livingston campus. You and the other publlo ofticiels interested in this issue will be provided more details shortly. I appreciate your mentioning this matter to mo and look forward to working with you to achieve a tuutually beneficial outcome.

I would aiso like to use this opporturity to provide information concerning the Rutgers Inseet Collection about which you recently wrote to me. Indeed it is ono of the most comprehensive collections of its lind and must be preserved for future use by students and researchors. My understanding of the current siturtion is that when the department of Entomolory was moved to a new fecitity several years ago, space and resources were not available to rolocate the museun at that time. Therefore, the collection wasileft in its orielyed location under the supervision of the Entomology Department.

Rutgers, particularly Cook College, is mder tremendous space constraints. The if university is in desperate need for new buildings to relieve the current serious overctowding but just as important, we need modern facilities to eteommodate the level of science expected from our faculty. Many of our laboratery facilities are antiguated and incapablo of sdequately supporting today's science. The univerity's ceppital campaign bas identified a number of new facilities that are absolutely necessary to attain the level of excellence to which we all aspire.

Old Queea's Building * 33 Sounerset Stroet - New Brenswick - New Jersey 08901-1281 - 7325932-7454- FAX: 732/932-8060 
$-2$.

In addition to the noed for new and more modem faclilities, Rutgen suffers trom a viery larise baciklog of doferred maintecance. The recent state supponted Higher Education Capitat Improvement Fund has helped reduce this backlog but funding was only availabie for approximately one third of the total identiflable need.

This background information is provided to plece in context the problem weige finche with the Rutgers lasect Colleotion. The sollection has been housed in une of our mort eatifinated buildings. The brilding known as J. B. Smith Hall, is in sueb bad condition that it unforturimoly is not stivegeable and is scheduled for demolition this fiscal year. As a resulk, alternative space is being sought to house the collection. If suitable space cen, not be found immediately, the collection may have to be temporarily pleced in storage. This option would be the last resort as the true value of the collection ean onily be realized when it is aceessible to otudents and facinty. I can assure you that the necessary stops will be taicen to preserve and make avatlable thin th collection, even if it requires a phased approach.

Thank you again for your kind words and for the pleasure of having lunch with you and Ellen last week. I look forward to working with you in the yeers ahead on the oppotunities and challenges facing higher education in New Jersey. Thank you for your support for Rutgers th.

Sincerely yours,

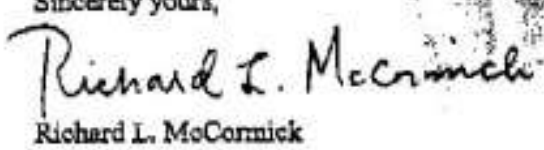

Richerd I, MoConnick 


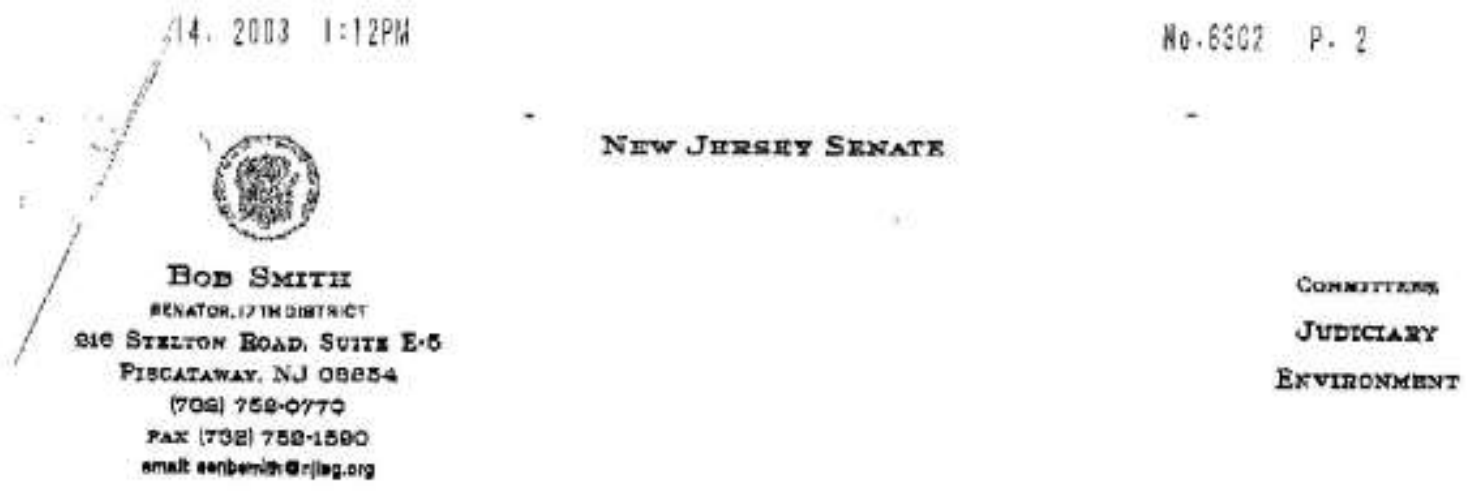

Juity 11, 2003

Presidens Richard L. McCormick

President's Office

Rutgers, The State University of New Jersey

Old Queen's, College Avenue Campus

83 Somerset Street

New Brunswick, NJ 08901

Dear President McCormick:

I am writing to thank you and all of the responsible faculty and staff at Rutgers for successfully finding a new home for the Rutgers University Entomological Musoum and its holdings.

Because of these efforts, a collection of significant scientific and historical value will remain well-preserved and necessible to the public.

As you know, the building that the collection is currently housed in, J.B. Smith Hall, is being demolished. After accepting the position of Professor of Entomology at Rutgers and Entomologist at the New Jersey Agricultural Experiment Station in 1889, Professor Smith was singularly responsible for formding the insect collection. Additionally, in 1903, wisen a fire broke out in New Jersey Hall, Smith and several of his students rushed into the building to save the collection from being destroyed. Since he was such an integral figure in the history of the vollection, and the building bearing his name will be leveled, would it be possible to have the room that it is to now be stored in, or the collection itself, be named in his honot?

Again, many thanks to you and your staff for taking the time to resolve this issue, While it angy not have seemed pressing in light of the other challenges facing Rutgers and your new administration, it is the smail, but significant treasures that play an important role in making Rutgers the great university that it is.

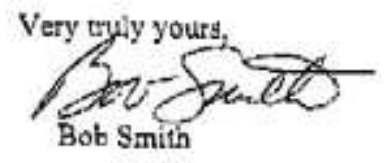

ROSimk 


\section{A.45, 5. 2008 8:5894 $3 \div-$

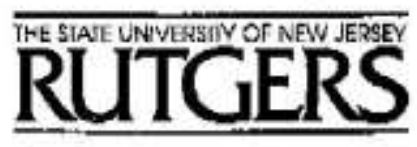

Richard L. MoCornick. Presidert

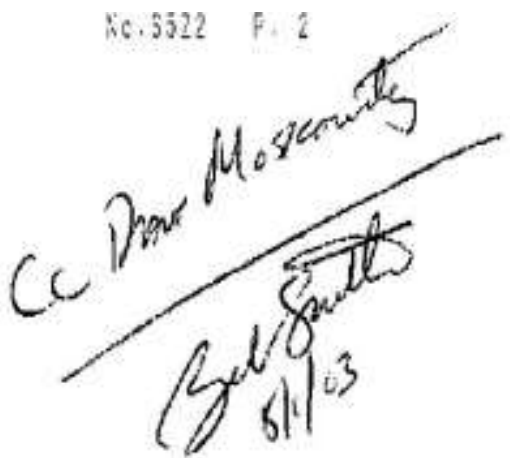

July 28, 2003

The Honorable Bob Smith

Suite E-5, 216 Stelton Road

Piscatawey, New Jersey 08854

Dear Bob,

Thank you for your kind letter of appreciation for the efforts of the staff at Cook College in reloesting the insect collection from J. B. Smith Hall to a space that meintains access to the public and continued use for teaching and research.

The collection has an important place in the history of Cook College. The revognition of Professor Smith and his role in the founding and preservation of this collection is a worthwhile goal and the Dean and staff at Cook Coljege aro supportive of such recognition.

We will begin to pursue the naming options available to us, whether it be the room in the McLean Lab where the collection is now housed or the collection itself, to ensure that suitable recognition is given to Professor Smith. The last location of the insect collection, ss you know, was the J.B. Smith Hall, which, after courtless yeans of valuable use, is nuw slated for demolition.

Thank you for your strong interest in Rutgers University. [ ern pleased to see your active participation in the work and life of the university, and in particular, your advocecy on behalf of the insect colleotion.

Sincerely yours,

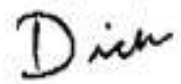

Riehard L. MeCormick

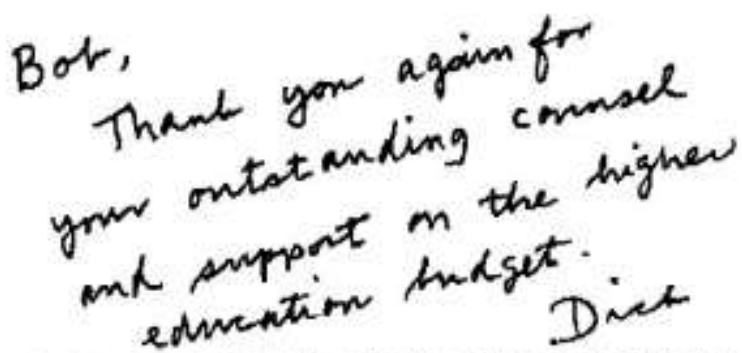

Old Queen's Building - 83 Somenet Screet - New Bruaswick - Naw Jerbey 08901-1281 • 732/592-7454 * FAX: 732/932-8060 
Just like the effort to save the insect collection in 1903, the 2003 relocation of the insect collection garnered media attention. For example, an article in the Sunday Star Ledger was titled, "Where Bugs Are Welcome - Insect collection has new digs."

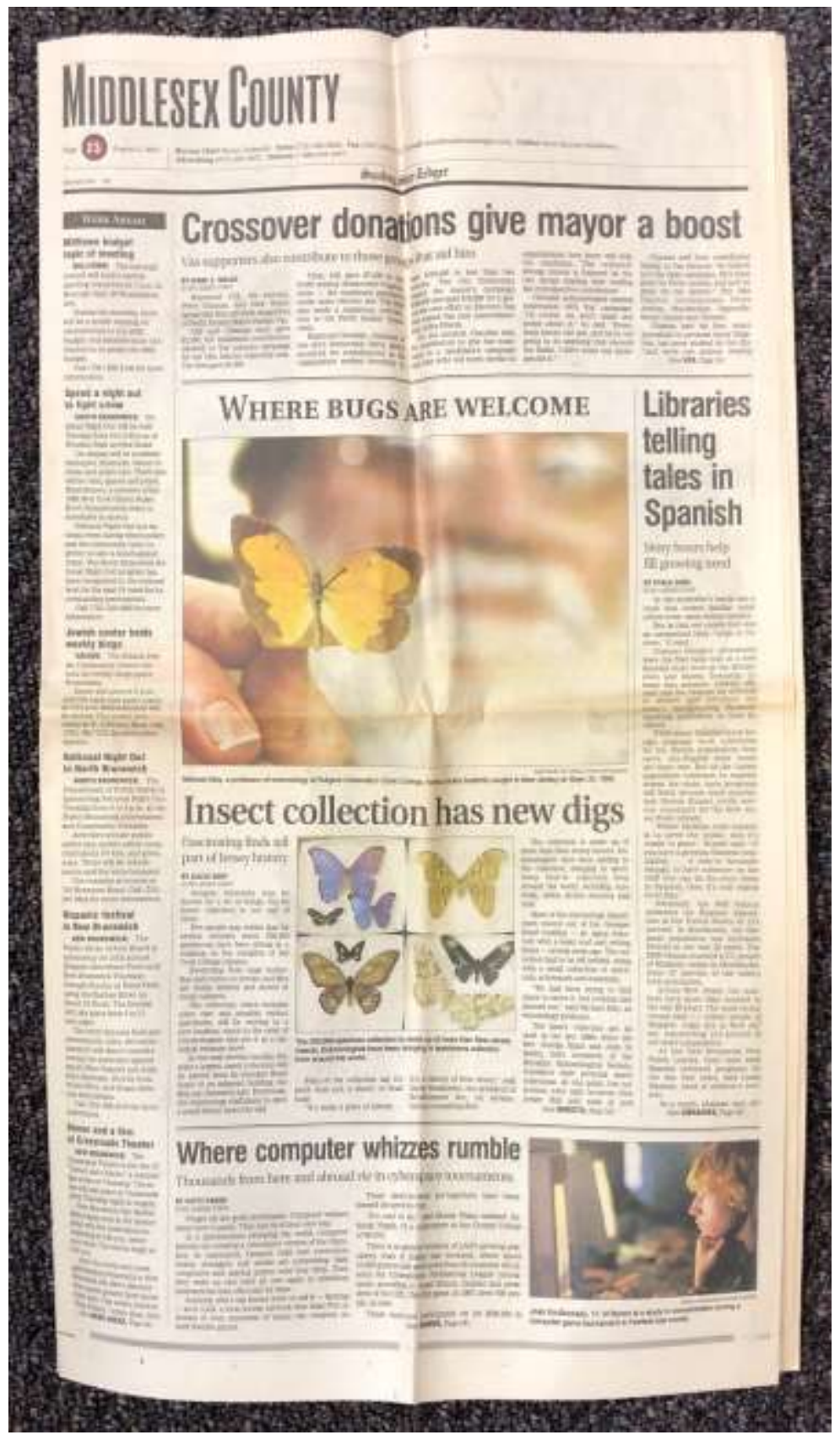

The Star Ledger article from August 3, 2003, featuring the Rutgers Insect Collection prior to its relocation to McLean Laboratories. 
Most of the insect collection now housed in the basement of McLean Laboratories is contained within the original floor to ceiling green steel cabinets in plexiglass-topped steel drawers. Some special collections like the Roberts' Hymenoptera are stored in wooden drawers with glass tops; through the efforts of Drs. Rachel Winfree and Frank Carle this collection has been catalogued. Odonata are housed in glassine envelopes in boxes. Each specimen is labelled with the date it was collected, where it was collected, and who collected it. Tray after tray in the cabinets are filled with insects painstakingly prepared by collectors that then donated their specimens to the insect collection for posterity. The collection continues to grow. Recent donations to the Rutgers insect collection include more than 8,000 pinned and labelled mosquitoes donated by the family of Dr. Darsie, over 1,400 Lepidoptera donated by Don Simonds, and a collection of New Jersey Tabanidae donated by Jeffrey Freeman. The collection represents a historical view backward through time at the insect fauna of the state and where they occurred. In many cases, the locations where the specimens were collected have been lost to development or other impacts, or the species have been extirpated and our no longer part of our biodiversity. Insect collections, like other biological collections, allow us to track what we have lost and what we have gained, important considerations for conservation efforts and understanding historic and emerging pest and beneficial species. The collection is meant to be for research, used by scientists for a widerange of entomological and ecological investigations. 


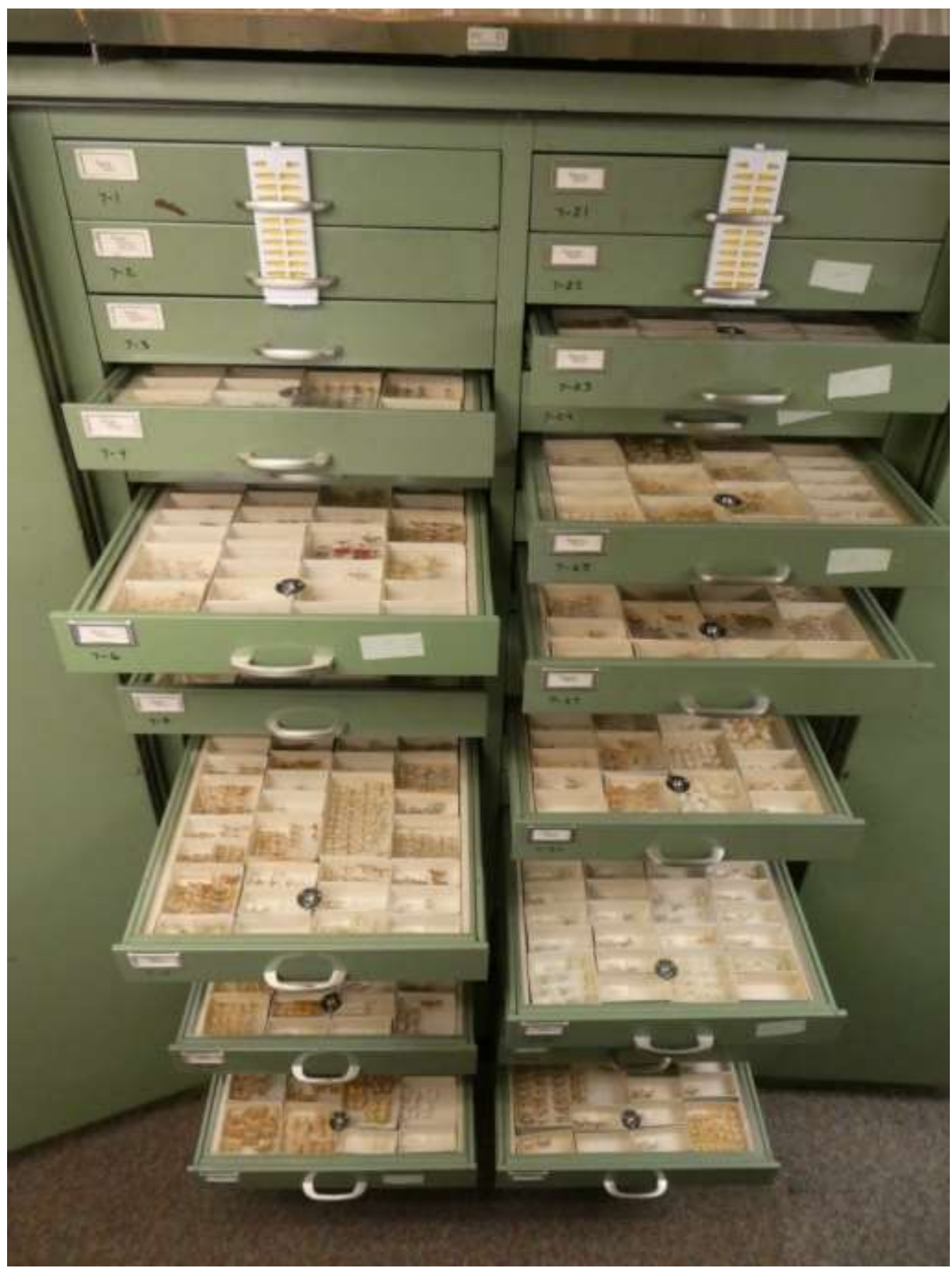

The majority of the Rutgers Insect Collection is currently stored in the green steel ceiling to floor cabinets purchased in 1957. Each cabinet has steel drawers with plexiglass tops that roll out for viewing. Personal collection of the author. 

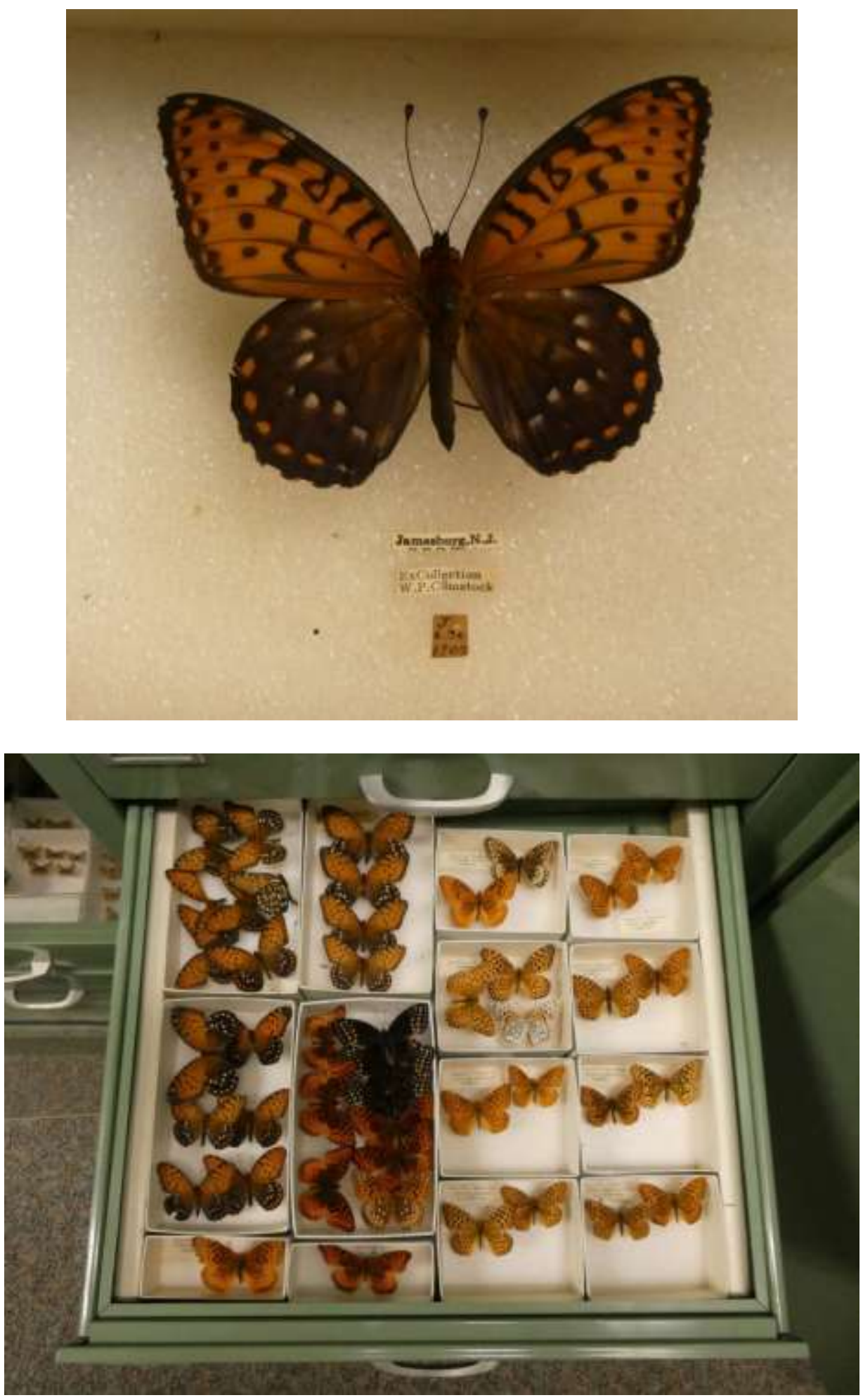

A Regal fritillary (Speyeria idalia) from the Rutgers Insect Collection collected on June 30, 1903 by William Comstock in Jamesburg, New Jersey (above) and a drawer from the collection showing additional Regal fritillaries collected in New Jersey (below). The Regal fritillary was last seen in New Jersey in the 1970s and is now considered extirpated. Personal collection of the author. 

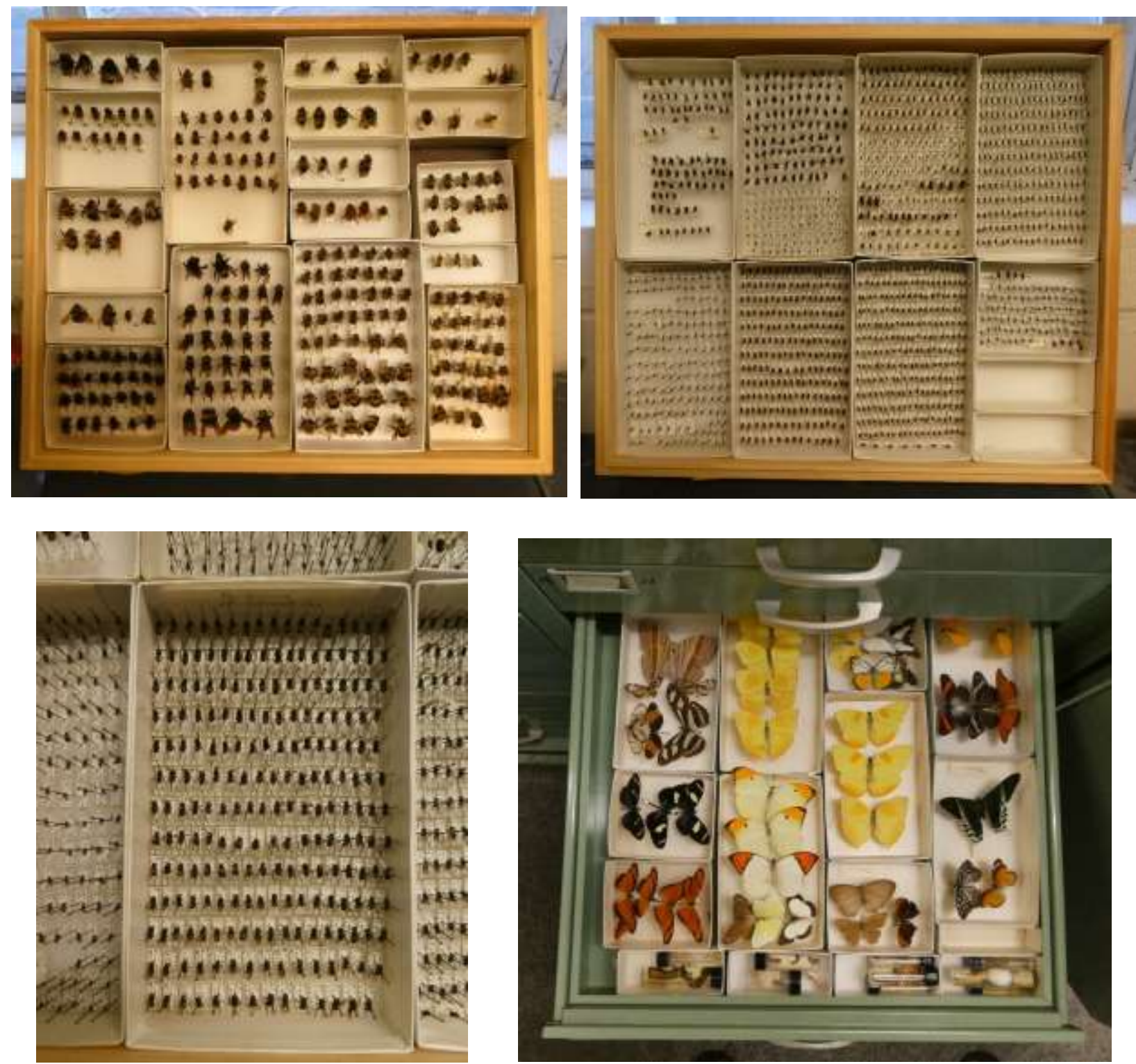

Drawers and Cornell wooden storage cases that house much of the insect collection. Each specimen is labelled with the collection date, location, and collector, and is arranged by taxonomy. Personal collection of the author. 


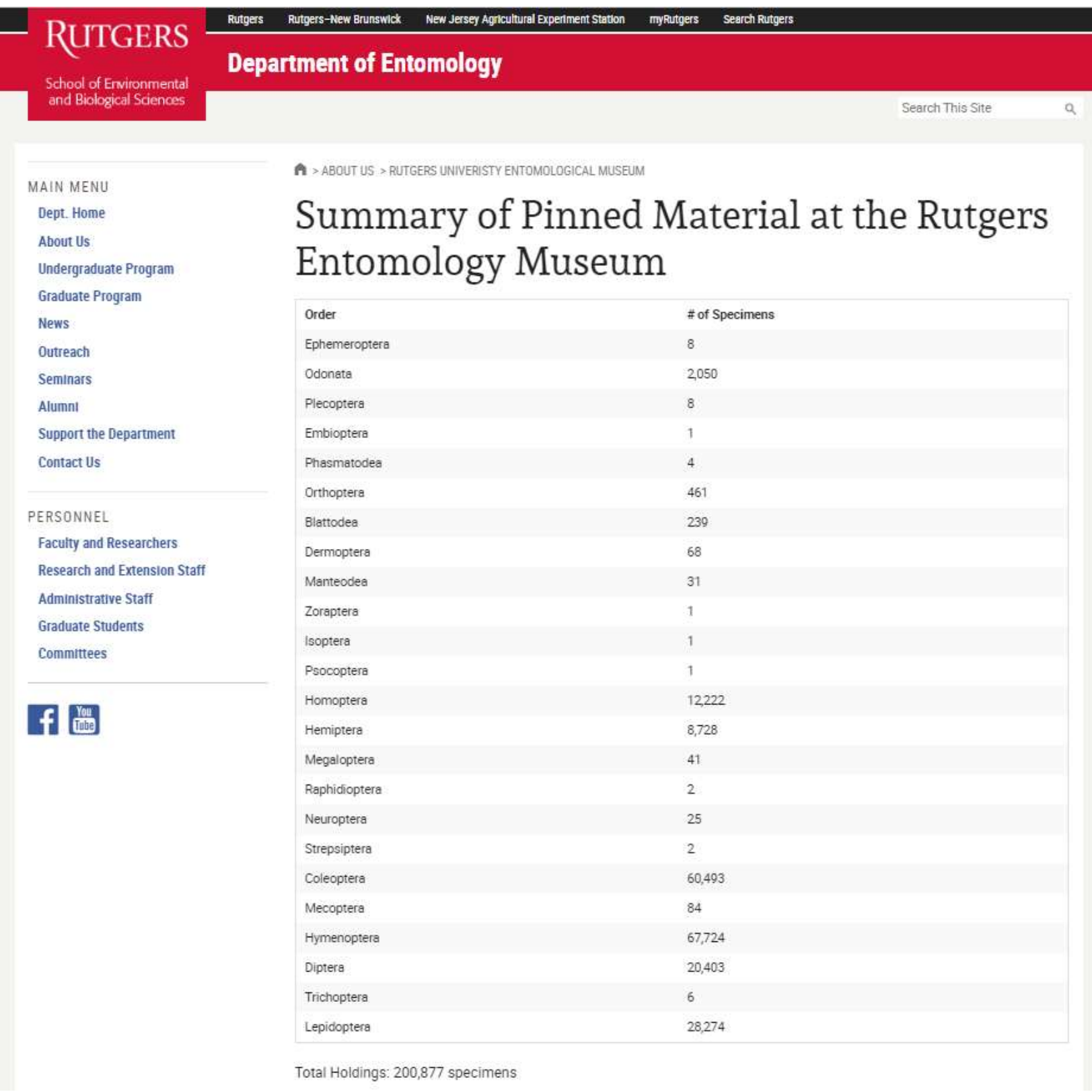

The most current summary of the insects in the Rutgers collection, although somewhat outdated. Retrieved on May 9, 2019 from https://entomology.rutgers.edu/museum/collection-summary.html

In a tragic corollary to what could have become of the Rutgers Insect Collection and with a direct connection to Rutgers entomology, on September 2, 2018, the Brazil National Museum was destroyed in a massive fire. The fire ravaged the museum, destroying the entomology collection. 
Within that collection were specimens of a termite thought to be new to science that were collected by two Rutgers University - Newark students pursuing their Ph.D. They had collected the specimens in the Rupununi region of Guyana, on the border of the Brazilian Amazon, in an area harboring some of the last remaining pristine tropical forests in the world. They were working on a description of the species when their collection was lost to the fire. ${ }^{68}$ In many ways, the Rutgers Insect Collection harbors similar species. While some were new to science when they were discovered and described by the great New Jersey entomologists working at Rutgers, perhaps equally important is that, like the rapidly disappearing tropical rainforests, many of these species were collected in habitats in New Jersey that have been long ago lost to development. In this regard, they represent a "library of biodiversity" of the state, allowing a look backward at our insect fauna over time.

In ending his 1979 essay on the history of the Rutgers Insect Collection, nearly 100 years after its inception, Dr. Schmitt shared his sentiments about the collection and the legacy it represents:

I remember one bright fall day at the time when I went into the "old" museum... The whimsical thought came to me that although their type specimens were safely stored elsewhere, surely the spirits of the late Rev. Dr. Hulst and Dr. Smith would be delighted with the scene - as surely as would the spirits of genial, beaming old Carl Ilg and, yes, Dr. Bailey Pepper too! Perhaps that thought will serve to end this account of the first hundred years of the Rutgers collections of insects. ${ }^{69}$

Now forty years later, with the collection once again safely protected, his vision still holds true.

\section{Rutgers Insect Collection Curators}

George D. Hulst (1888-1889)

John B. Smith (1889-1912)

\footnotetext{
${ }^{68}$ Catherine Carrera, "How Brazil National Museum fire halted Rutgers discovery of new bugs," NorthJersey.com, 28 February 2019, https://www.northjersey.com/story/news/2018/10/01/brazil-museum-fire-halts-rutgers-work-newbug-species-termites-dragon-fly/1373705002/.

69 J.B. Schmitt, “A History of the Insect Collections at Rutgers University, 1879-1979," Rutgers.edu, 28 June 2019 , https://entomology.rutgers.edu/museum/history.html.
} 


Thomas Headlee (1912-1936)
Carl Ilg (1921-1936)*
John Schmitt (1936-1974)
Robert F. Denno (1974-1976)
Radclyffe Roberts (1976-1980)
G. William Wolfe (1980-1990)
Michael May (1990-1995)
Karl Kjer (1996-2015)
Frank Louis Carle (1996-2014)*
Frank Louis Carle (2015-2019)
*Assistant Curator

David Moskowitz holds a Ph.D. in Entomology from Rutgers University. He is a Senior Vice President with EcolSciences, Inc. in Rockaway, New Jersey and has been with the company for thirty-three years. Dr. Moskowitz is also the co-founder of National Moth Week (nationalmothweek.org), an international event held each year in the last week in July, and one of the largest Citizen Science projects focused on insects. He also created the Facebook Group Bug Addiction - Confessions of a Bug Addict and has published numerous papers on insects and other wildlife in peer-reviewed journals and popular nature-based publications.

The author would like to thank a great many people assisted with this paper, including Dr. Frank Carle who provided access to the Rutgers Insect Collection, Dr. George Hamilton who provided historical photographs and papers about the Rutgers insect collection and Entomology Department, Dr. Marc Epstein who generously shared his research notes on Dyar, Smith and Hulst, Dr. Mark Robson, Dr. Michael May, Dr. Marc Slaff and Dr. Michael Gochfeld who reviewed the draft and provided suggestions that greatly improved the paper, Dr. Lisa Reed who provided photographs of the insect collection being moved and suggestions to improve the manuscript, Richard Walling for assistance with early newspaper archives and Alan Moskowitz for suggestions on filling research gaps. Two anonymous reviewers also provided suggestions that improved the manuscript and one of these reviewers filled in gaps in the history. I am also 
appreciative of the access provided by the Rutgers University Special Collections to historical photographs and documents and the American Museum of Natural History for access to the Hulst and Smith Lepidoptera collections. Thank you is also due EcolSciences, Inc. for the time and resources to prepare this historical account. Finally, a special thank you is due Melissa Ziobro for her encouragement to write this history. 